ON

\title{
ANEURISMS OF THE HEART;
}

WITH CASES.

BY JOHN THURNAM.

READ JANUARY 23D AND FEBRUARY 13TH, 1838.

Partial dilatation or aneurism of the heart, in the proper application of the term, is a disease the existence of which has been known to physicians and pathologists since the publication of the cases of Walter, Baillie, and Corvisart; but which attracted very little of their attention until 1827, when the occurrence of several cases nearly simultaneously at Paris, lead to the publication of an important memoir on the subject by M. Breschet*. In this memoir, the author gives the history of ten cases, from which he attempts to deduce conclusions as to the nature, causes, and symptoms of the disease; admitting, however, the insufficiency of the facts with which he was acquainted for affording a perfect history of the affection. Since the publication of $\mathbf{M}$. Breschet's memoir, some further researches, chiefly as respects the pathological anatomy, have been instituted, and several cases have, from time to time, been published. The additional facts and observations which have thus accumulated,

" Répert. Gén: d’Anat., \&c. Tom. III. p. 181. 
are in several respects calculated to invalidate some of the conclusions arrived at by M. Breschet, and would appear capable of furnishing, at the least, some new inferences.

My attention was first strongly directed to this disease, by the occurrence of a remarkable case of it in the Westminster Hospital, which will be the first narrated in this paper. I have since visited the different museums of this metropolis, and that at Fort Pitt, Chatham, and have thus had an opportunity of inspecting, at the least, twenty-five specimens of the lesion in a more or less advanced stage. Of these cases, I found that the greater proportion had not been published at all, and that many of the remainder had only been very imperfectly described in catalogues. Of the appearances of the disease in all these cases I have taken notes, and have endeavoured to obtain as much information respecting their history as possible; and in some instances, have succeeded in obtaining tolerably complete cases, which have been very obligingly confided to my disposal. The new cases with which $I$ have in this way become acquainted are thirteen in number, and of these, eight I have detailed at length ; of the others, the accounts are too defective for this purpose, but such particulars as I have been able to collect respecting them, as well as of others before described, I have availed myself of, and have arranged in an appendix to this paper, which contains every case of the affection with which I am acquainted. The materials thus collected are very considerable, amounting altogether to 84 cases, of which 58 are in the left ven- 
tricle. With such a number of facts before us, I cannot but conclude that a history of this disease may be formed, more complete than any we have hitherto possessed.

The almost endless discussions, which have so long existed, as to the nature of arterial aneurisms have, to a certain extent, found a parallel in those which have arisen respecting the same lesion in the heart; even during the comparatively short period that pathologists have been aware of its occurrence in this situation. As in the case of aneurism of the arteries, so also in that of the heart, the views of some pathologists who have treated of the disease have been too limited, in contending, as they frequently have, for its production only in one mode. By some, all these cases have been considered as so many instances of false aneurism of the heart, produced by rupture or ulceration of one or more of its coats; whilst others have chiefly advocated the doctrine of true aneurism, or that by dilatation. In the course of this paper I believe that I shall be able to adduce evidence to the erroneous character of these exclusive views, and in favour of the position that we ought to admit the existence of both these primary forms of aneurism of the heart, as well as of several varieties of these produced in distinct ways.

Aneurisms of the heart have, as already stated, been met with most frequently in the left ventricle; but there are some undoubted cases of its occurrence in the left auricle; and the valves of the heart have themselves been found, in a few rare instances, to be the seat of dilatations, which may, with propriety, be re- 
garded as aneurismal. I intend to consider the disease as it is met with in these three situations.

\section{ANEURISM OF THE VENTRICLES OF THE HEART.}

It is a striking circumstance that, so far as we are at present aware, the right ventricle is altogether exempt from this lesion. This fact was, by $M$. Breschet, adduced as confirmatory of the view which he has taken of the mechanism of its production; and he supposes that the right ventricle is not subject to aneurism, in consequence of its apex being, relatively to the thickness of its lateral walls, much stronger than that of the left ventricle, and consequently better able to support an equal degree of distending force. M. Cruveilhier, also, entertains similar views. It appears to me, that the non-occurrence of aneurism in the walls of the right ventricle cannot be satisfactorily explained in this way; but that, so far as physical circumstances are concerned, it must be attributed to the difference in the function of the tricuspid and mitral valves; the former, in the normal state, permitting considerable, the latter little or no regurgitation of blood. This less perfect closure of the auriculo-ventricular opening on the right, than on the left side, has long been admitted by physiologists, but has been lately more fully insisted upon and demonstrated by Mr. T. W. King. This gentleman attributes what he has called a " safetyvalve function" to the tricuspid; and concludes from his researches that its closure is the less complete in proportion " to the increasing degrees of the ventri- 
cular distention "*. Admitting the existence of this regurgitation, as permitted by the tricuspid valve, it will readily be seen that the walls of the right ventricle must be much less subject to active distention during the ventricular systole, than those of the left, a difference which, of itself, would appear to me adequate to account for the immunity from aneurism which the right ventricle seems to possess.

But there are other considerations irrespective of the mere mechanism and physical conditions of the parts concerned, and connected with their functions and vital properties, which would lead us altogether to deny the name of aneurism to any form of dilatation that may be met with in the right cavities of the heart. The right heart, to adopt the language of some comparative anatomists, is, we must recollect, in man and the warm-blooded vertebrata, the centre of the circulating system of black blood; the centre in fact of the venous system; just as the left heart is the centre of the arterial system. It is well known that the diseases of the arteries have a character different from those of the veins; a circumstance which is probably dependent not merely upon a diversity in the structure of their coats, but also upon a difference in the vital endowments of the two kinds of blood which they contain. We hence find that, by common consent, the term aneurism has been restricted to dilatations of the arteries, whilst varix is that which has been given to a corresponding

* Guy's Hospital Reports, Vol. II. p. 104. 
lesion occurring in veins; and, as a remarkable fact, I may observe, in passing, that there does not appear to be on record a single authentic case of lateral or sacculated aneurism of the pulmonary artery, a vessel which, properly speaking, and as regards function, is a vein *. It appears to me that, to consider the subject philosophically, the same distinction ought, at the least, to a certain extent, to be drawn between the partial dilatations of the right and left hearts, as between those of the two systems of vessels to which they are respectively the centres; and this view would certainly appear to be supported by observation, as far as that has already been carried.

Should the propriety of this distinction be conceded, I think it may not be without its use to attempt a definition of aneurism, founded upon it. By the term aneurism then, as employed in this paper, I understand, an abnormal dilatation of a portion of the vascular system of red blood, either dependent upon, or necessarily connected with a morbid change in the tissues forming the walls of the dilated part. This definition will of course exclude not only all forms of dilatation of the right cavities of the heart and of the pulmonary artery, but also all general dilatations of the left cavities of the heart ; different forms of which, either combined or uncombined with hypertrophy, have since the days of Baillou and Laucisi been generally known under the name of aneurism. The inapplicability, however, of

* See a Paper by the Author in the Edinburgh Medical and Surgical Journal. Vol. XLIV. p. 75. 1835. 
this term, as applied to these lesions, has not been unperceived by authors; and especially by Morgagni, Corvisart, and Andral ; but nevertheless they have all of them by their example sanctioned its employment.

I cannot at all agree with $M$. Bouillaud in the opinion that these objections are ill founded, nor believe that there is not "any essential difference" between the simple dilatations of the heart and arterial aneurism*. This author has indeed endeavoured to trace an analogy between the general dilatation of one of the cavities of the heart, and the fusiform or diffused true aneurism of an artery, such as is so often met with, involving the whole circumference of the aorta $\uparrow$. Between the two lesions there appears to be this important distinction, that in the dilated aorta, the tunics are uniformly diseased, whilst in the simply dilated ventricle, the tissues are healthy, or at the least not necessarily altered. When the dilatation is accompanied by hypertrophy, the enlargement must frequently be regarded as altogether physiological; or as a change which enables the heart to overcome, at all events for a time, various obstacles in the course of the circulation. On the whole, then, simple dilatation of the heart appears to me to be a change, in virtue of which this organ accommodates itself to the reception of an increased quantity of the circulating fluid, and as analogous not to the aneu-

* Traité Clinique des Maladies du Cœur. 1835. Tom. II. p. 524.

† Dict. de Méd. et Chir. Prat. 1829. Tom. II. Article "Anévrisme." 
rismal dilatation of the arteries, but to that physiological, spontaneous, and uniform enlargement, of which they are not unfrequently the seat; as may be seen in the arteries of the uterus during gestation; in those supplying parts which are the seat of hypertrophy or of tumours; and especially in the anastomosing branches of arteries, by means of which a collateral circulation is established after the main artery of an extremity has been tied, or even when the aorta itself has, from disease, been nearly obliterated. When it shall have been further shown, that almost every form of aneurism which has been met with in the arteries, is occasionally found in the heart itself, I think we shall be fully justified in concluding that simple dilatation ought to be considered as a lesion distinct from aneurism, and as having other analogies.

I shall now proceed to the consideration of the disease as it occurs in the left ventricle; which is not only its more frequent but also its more important situation. In the first place, I shall narrate some interesting cases not before published, which I trust will in some degree add to our knowledge of its pathology, if not also to that of its symptoms and diagnosis.

\section{CASE I.}

Three Aneurisms of the left ventricle of the heart, consecutive to Rheumatic Pericarditis.

George Mills, aged 28, a tall, well made man, but evidently much reduced by disease, by trade an up- 
holsterer, was admitted into the Westminster Hospital, December 13th, 1836. I found him in the ward, sitting upon the edge of his bed, breathing very laboriously, and supporting his head upon the back of a chair. His face bloated, lips livid, features contracted and expressive of the greatest anxiety.

He complained solely of the extreme difficulty of breathing, and of severe pain under the lowest part of the sternum, extending backwards to the spine. The pulse, not distinguishable at the wrist, 108 in the brachial arteries, very feeble and thready ; inspirations 40 in the minute; tongue covered in the centre with a thin white fur, livid at the margins; loss of appetite ; extreme thirst; nausea and sometimes vomiting. The urine passed freely ; considerable œdema of the legs and feet, also of the cheek when in the recumbent posture; surface generally, and the feet particularly, very cold.

Physical signs. - Resonance, upon percussion over the chest generally, pretty good; but the cardiac region not carefully examined in this way. The place of the normal respiratory murmur supplanted by a combination of sonorous and mucous wheezes; the former prevailing anteriorly and superiorly; the latter posteriorly and inferiorly. Motion and impulse of the heart felt over the whole front of the chest; rhythm disturbed; sounds indistinct, with a slight bellows-murmur to the left of the sternum.

He stated that he had uniformly experienced good health, until about eighteen months ago, when he fell off the top of a coach, and "strained himself inwardly." 
He also suffered, at the same time, from acute rheumatism, chiefly of the right knee joint; and which, according to his brother, was accompanied by pain in the chest. He became a patient in this hospital under the care of Dr. Roe, July 8th, 1835, and was discharged "cured," according to the hospital register, on the 28th of the same month. Since this illness he has never been quite well, gradually declining in strength and vigour; though not until within the last three months, to the extent of preventing him following his usual employment. About this time he was rather suddenly seized with pain in the chest and difficult breathing, which have gradually increased, and have for some time been combined with anasarca.

He has applied, at different times, to two or three practitioners, by whom bleeding, leeches, and blisters have been prescribed, but with very slight relief; he lost about 24 ounces of blood two weeks since. He has been in the practice of taking a considerable quantity of fermented liquor daily; but his habits have been what are generally called temperate.

Diagnosis and treatment. - Dilatation and hypertrophy of the heart, possibly with constriction of the mitral orifice, the effects of an antecedent, acute endopericarditis. To take an ounce of the julep of ammonia (Pharm. Guy.) every second hour; to drink freely of a warm solution of bitartrate of potass, containing a moderate quantity of gin; and beef-tea diet.

December 14th. The same as yesterday. Dr. Burne saw him in the course of the day, and examined his chest, and was satisfied of the existence of 
a rather feeble bellows murmur. He directed the remedies to be continued, and an ether draught to be given at bedtime. Towards evening, the patient, for the first time, obtained a little relief from the dreadful difficulty of breathing, and seemed to rally a little, but still the sitting posture was the only one supportable.

December 15th, 3 A. M. I was suddenly called to him. Whilst talking to his wife, the dyspnœa had all at once increased, and falling backwards he had expired.

Dissection, twelve hours after death. Thorax.Upon elevating the sternum, the heart was seen to be of immense size, occupying the entire centre of the thoracic cavity, and encroaching very much on the lungs. The pleuræ on both sides were free from marks of disease; except that the portions covering the concave surfaces of the lungs inferiorly, were, on both sides, adherent, either by strong bridles of membrane, or by a lax cellular tissue, to the opposed surfaces covering the pericardium. The lungs did not present any organic alteration of tissue; but were very considerably affected by venous congestion, and œdematous infiltration.

Heart.-The opposed surfaces of the pericardium were almost universally coherent through the medium of a spongy cellular tissue, which, in some places, was infiltrated with serum.

All the cavities of the heart, but especially those of the right side and the left auricle, were consider- 
ably dilated; but the walls of these three cavities were scarcely thicker than in health: the hypertrophy here being chiefly by increased extent. There was very considerable eccentric hypertrophy of the left ventricle; its cavity being capable of containing a large orange, whilst its walls, at their thickest parts, exclusive of the adherent pericardium, measured a full inch. Near the base of this ventricle, the muscular substance had, in two or three places, become replaced by a dense fibro-cartilaginous tissue, which connected the pericardium and endocardium to each other. With the exception of slight gelatinous thickening of the free border of the tricuspid valve, the lining membrane and valves of the right side of the heart were healthy. The sigmoid valves of the aorta, as well as the arch of that vessel, were free from disease. The mitral valve was thickened cartilaginously at its free border; but it was not shortened, and it appeared capable of closing the enlarged auriculo-ventricular opening. The endocardium of the left auricle had an opaque and yellowish appearance; and a very delicate pellicle was capable of being scraped, or rather peeled from its surface, leaving a denser and whiter stratum beneath.

Before cutting into the heart, it had been noticed that, in addition to its prodigious size, it had a very irregular shape; the left ventricle being, as it were, lobulated. This was found to depend upon the presence of three aneurismal dilatations of the walls of this ventricle, which were partially filled with layers 
of fibrine, such as are usually met with in arterial aneurisms. The first of these examined was seated in the posterior part of the side of the ventricle near its base; and behind the tendinous cords of the mitral valve, by which its opening into the ventricle was covered. It was about the size and shape of half a lemon cut transversely, and was only slightly constricted at its mouth. In the wall of the ventricle just below this, a second aneurism existed, which, however, was not larger than a good-sized filbert. A third, which was by much the largest; and which appeared to have been formed by the union of two dilatations originally distinct, communicated with the ventricle by a large elliptical opening seated in its anterior wall; and it was this which formed the most prominent tumour externally, rising up beneath the origins of the great vessels. It was biloculate, and each cavity was about the size of an egg or small orange.

Upon removing all the fibrinous layers from the two larger aneurismal sacs, they were found to be constituted almost solely of the pericardium, none of the muscular fibres of the ventricle traversing them. The lining membrane of the ventricle, at the margins of the openings of the two larger sacs, had become converted into dense fibro-cartilaginous rings, which were continuous with a rugose kind of tissue lining the sacs, but not apparently separable as a distinct membrane. The small aneurism differed from the two others in being imbedded in the muscular sub- 
stance of the heart, and also in being very distinctly lined by the internal membrane of the ventricle, tolerably smooth and unaltered.

The portions of the ventricle which have been described as having undergone the fibro-cartilaginous degeneration were in the immediate vicinity of the aneurisms. The heart, when emptied of its blood, weighed 32 ounces troy.

Abdomen.-The liver was slightly mottled and granular. The kidneys somewhat enlarged, their cortical portions of a pale livid hue. The rest of the abdominal and pelvic viscera healthy.

The nervous system was not examined.

This case is one of great interest in several respects. In the first place, the lesion was of unusually great extent, there being three, and, as it would appear, originally four aneurismal sacs.

The anatomical characters of the smaller aneurism in this case appear to me strongly to support the view, that lateral aneurism of the heart originates, frequently, in the dilatation of all the coats of that organ. We have here also, I think, an example of this disease consequent upon rheumatic pericarditis. The history points directly to the existence of this affection, and the universal adhesion of the pericardium found after death sufficiently attests it. The inflammation had evidently extended to the muscular substance of the heart, and had produced the fibrocartilaginous deposit, an anatomical condition which differs from, and must not be confounded with, the 
fibro-cellular degeneration of muscular tissue consequent upon pressure and other causes, and which is alluded to by M. Cruveilhier as a cause of partial dilatation. The walls of the ventricle thus altered by the consequences of the inflammation which had probably likewise implicated the lining membrane, would be obviously less capable of sustaining the force of the blood under the influence of the ventricular systole, and might readily become dilated in their weakest points. In the great majority of cases of aneurism of the heart, the adhesion of the pericardium is limited to the surface of the sac, and is doubtless a secondary lesion, attributable to the pressure of the tumour on the opposed surface of this membrane. In this case, however, I believe that the sequence of morbid phenomena was reversed, and that the affection of the pericardium was the primary lesion. It may perhaps be thought that the formation of the aneurisms was due not to the rheumatic affection, but to the " inward sprain," which might have been attended by an imperfect rupture of the muscular fibres of the heart. The fact, however, of there having been four aneurisms, and the smallest of these being evidently lined by the endocardium, would appear to me sufficient to refute such a supposition. With the exception perhaps of Dr. Elliotson's case $\left(27^{*}\right)$, this is the only one I am acquainted with, which shews the direct connexion between rheumatic pericarditis and lateral aneurism of the heart.

\footnotetext{
* Thre references throughout this division of the paper, are made to Appendix A.
} 
With respect to the symptoms, it need scarcely be observed, that they sufficiently announced far advanced disease of the heart, with obstruction to the pulmonary circulation. The existence of the bellows murmur led me to infer the presence of valvular disease, in addition to hypertrophy and dilatation of the cavities. But the valves appeared to be adequate to the performance of their functions, and I presume that the bellows sound must be referred to the passage of the blood through the mouths of the imperfectly filled aneurismal sacs.

\section{CASE II.}

Immense Aneurism of the Apex of the Left Ventricle of the Heart. Sudden Death.

For the particulars of this case, I am indebted to the kindness of Mr. Kiernan, who possesses the preparation, and of Mr. Percival of Earl Soham, Suffolk, who made the examination of the body, about the year 1830 .

Tatham, aged about 23, a pot-boy, fell down dead suddenly in a street in the eastern end of the metropolis. He had been a patient in the London Hospital, and bore evident marks of active treatment, from cupping, leeches, and blisters over the chest; but beyond this, nothing could be learned respecting his history.

Dissection.-An immense aneurismal tumour was met with growing from the apex of the heart, in a continuation of the longitudinal axis of which it was situated. Between the aneurism and the heart, there 
existed a rather deep constriction, which gave the diseased organ an hourglass-like appearance, before it was laid open. The sac, which was as large as the heart itself, and had even a greater circumference, opened into the left ventricle of the heart at its apex; and was formed almost exclusively of the two layers of the pericardium which were strongly adherent in this situation, but which were free through the rest of their extent. Around its mouth, which was about two inches in diameter, and was not furnished with any projecting lip, the lining membrane of the ventricle was somewhat opaque and thickened; and, accompanied by a thin substratum of muscular fibres, appeared to be traceable for about an inch into the interior of the sac, with the rugose interior of which it became almost insensibly blended. The sac was filled with the densely laminated fibrinous coagula peculiar to aneurisms. In other respects the heart was healthy. Mr. Percival is also pretty sure that there was fluid to some amount in the chest, and that there was great engorgement of the lungs*.

From the advanced condition of the lesion it is not very easy, from an examination of the specimen, to come to a satisfactory conclusion as to its mode of origin in this case; so far, however, as the appearances go, they appear to favour the idea of its having been originally a true aneurism, or one by dilatation.

* Mr. Wardrop has had a plate engraved of this beautiful pathological specimen, which he intends giving in his work, on diseases of the heart, now in progress of publication. 
It is much to be regretted, that no complete history of the case can be obtained, for one would suppose that its existence could hardly fail to have been announced by remarkable signs, both rational and physical, and that it could scarcely have escaped detection during life, had a tolerably careful manual and auscultatory examination been made. That serious symptoms had existed is sufficiently evident from the numerous marks of cupping, \&c., found on the chest after death. From the situation of the tumour, depressing as it must have done the diaphragm, it would appear probable that, from its bulk alone, it would have interfered directly and materially with the functions of that muscle; and probably also with those of the digestive organs.

The following case occurred in the practice of Mr. Langstaff, to whose courtesy I am indebted for the opportunity of communicating it to the Society.

CASE III.

True Aneurism of the base of the left Ventricle of the Heart. General Dropsy; Diseased Liver and Spleen.

Hannah Davis, aged 52, the mother of six children, was admitted into the Cripplegate Workhouse, December 22d, 1817.

Upon examination, it was found that she was suffering from ascites, with anasarca both of the upper and lower extremities, and of the face; that the breathing was performed with the greatest difficulty; the face suffused; pulse 120 , very small, but regu- 
lar; urine small in quantity, high coloured, and voided with pain.

It appeared that she had been long addicted to dram-drinking; that her health had been declining during two years; and that the dropsical symptoms, which had appeared about twelve months ago, had since that time gradually gone on increasing. She had twice been an in-patient at St. Bartholomew's Hospital during that period.

The evidence of organic disease, of an incurable kind, being so very obviously denoted by the symptoms, and there being every probability of her not living many days, the operation of paracentesis was not proposed. The difficulty of breathing became almost hourly more distressing until December 24th, when she died.

Dissection.-Abdomen._There were nineteen pints of yellow serum in the peritoneal cavity. The liver was greatly enlarged, granulated, and easily torn; its blood-vessels were also surprisingly congested. The spleen was double its ordinary size, and its capsule was partly cartilaginous and osseous.

Thorax.-There were firm adhesions of the right pleura anteriorly, and about two pints of fluid in that cavity. The lungs on both sides were loaded with blood and water, and retained the impressions of the fingers. There were nearly four ounces of watery fluid in the pericardium. The valvular apparatus of the heart was quite healthy; and with the exception of a thickened state of the appendage of the right 
auricle, and a somewhat dilated condition of the left ventricle, this organ appeared quite free from disease, until by chance the fleshy columns of the mitral valve were divided, which led to the discovery of a real aneurism of the ventricle.

The aneurism was evidently one by dilatation, its cavity would have contained a moderately sized Orleans plum; it was situated at the posterior part of the base of the ventricle, behind the posterior and left lamina of the mitral valve. The mouth of the sac measured about an inch in its longest diameter, and was without any projecting lip or rim; in its immediate neighbourhood, the lining membrane of the heart was opaque and whitish, and was most distinctly traceable into the sac, which it lined throughout, its opaque and thickened condition being still more obvious in the centre. There was not the least sign of the fibrin of the blood having become deposited upon it. The sac did not project so as to form any aneurismal tumour on the external surface of the heart, but upon dissecting off the reflected layer of the pericardium, this membrane was found to be in close apposition with a large portion of its more convex part, which was not traversed by any muscular fibres, and had a continuation of the trunk of the left coronary artery passing over it.

The aorta was thickened, and partly changed into cartilage.

The aneurism in this case had evidently been produced by dilatation, and would appear to have origin- 
ated in the diseased condition of the lining membrane, exemplifying the mode of production which has been contended for by Reynaud, Ollivier, (d'Angers*,) and Carswell. A preparation in the museum of St. Bartholomew's Hospital (30) bears considerable resemblance to this, and both of them may be said to be instances of aneurisma herniosum. The patient can hardly be regarded as having died of the aneurism; the fatal dropsy evidently being dependent upon organic changes in both the abdominal and thoracic viscera.

For the following case I am indebted to the kindness of Dr. Macreight ; and also to that of Mr. Alexander Shaw, in whose collection the preparation is deposited.

\section{CASE IV.}

Diffused True Aneurism of the lower half of the left ventricle of the heart, with extensive ossification of the atrophied muscular tissue.

Charles Lidcke, aged 75, a tailor, a patient of the Marylebone Dispensary, under the care of Dr. Macreight. In early life he was of intemperate habits, but enjoyed general good health.

During the last three years, he has suffered from difficulty of breathing and palpitation, with pain and a sense of weight in the region of the heart, which were much increased by the least exercise. The dyspnœa became so severe, that during the last

* Dict. de Méd. $2^{\text {me }}$ ed., Tom. VIII. 1834, p. 303. 
month he required to be propped up in bed in the sitting posture, with the chest inclined forwards. The pulse was extremely weak, but he could not bear any stimulant remedies, from their causing increased pain in the region of the heart. Anasarca occurred a few days before death.

Dissection, (by Mr. Graham, January 6th, 1836.) -Thorax.-The mucous membrane of the trachea and bronchi presented traces of slight vascular congestion. The cartilages of the trachea were harder than usual. The lungs were free from disease. The pericardium contained about half a pint of fluid. The heart was large, and had white opaque lines on its surface, caused by ossification of the branches of the coronary arteries. On the right side of the heart, no deviations from healthy structure were met with, excepting a few osseous specks in the right auricle. The mitral valve, with its tendinous chords, was a good deal thickened, and the former was studded with osseous points and spiculæ. The upper part of the walls of the left ventricle was hypertrophied, but its lower portion was very much thinned and dilated. The dilated part would contain a small orange, its walls were thinnest at the lowest part, where they did not much exceed two lines in thickness, whilst nearer the middle of the ventricle they had a thickness of from four to five lines, and above this they gradually became continuous with the hypertrophied, but otherwise healthy muscular tissue of the base of the ventricle. The aneurismal portion of the ventricle presented only slight traces of muscular fibres, their 
place having become occupied by a whitish cellulo. fibrous tissue; the alteration being most advanced at the lowest part of the dilated ventricle. This cellulofibrous tissue was the seat of a very considerable osseousdeposit; a large, bony plate having been formed, which externally dipped down into the atrophied muscular tissue, and internally presented a rough surface, covered by the lining membrane of the ventricle. Scarcely any traces of the natural fleshy network remained in the dilated portion of the ventricle; the endocardium lining it was entire, but in many places white and opaque. There was no coagulum attached to its surface. The sesamoid bodies of the aortic valves were large and ossified; as was likewise the arch of the aorta and the large vessels given off from it.

Abdomen.--The liver was paler than in health, and resembled that of drunkards. The other abdominal viscera were healthy.

With respect to the nature of the aneurism in this case, it cannot, I think, be doubted that it had its origin in dilatation, which, however, was remarkable from extending over so large a portion of the ventricle. The case may correctly enough be regarded as one of " diffused true aneurism," and as analogous to the dilatation of the whole circumference of an artery. In the extensive ossification of the atrophied and transformed muscular tissue, we have a very interesting feature, which has no parallel in any of the other cases which I have collected. I cannot help suspecting that some of those rare cases 
of ossification of the muscular substance of the heart which we find on record, have been attended by this form of aneurismal dilatation.

The extremely weak pulse, and the general type of the symptoms were such as are reconcileable with the very defective contraction of the left ventricle, which must have existed in connexion with such a condition in the centre of the circulating system. The dropsy, also, which occurred shortly before death, was no doubt principally dependent upon this increasingly defective action of the heart. The peculiar modification of pain which was experienced in the præcordial region, or that of an oppressive sense of weight, is a symptom which I incline to believe will be found one of the more constant of those which belong to aneurism of the heart in its more advanced forms.

Aneurism of the heart was known to John Hunter at a period very long anterior to the publication of the first British case of the disease by Dr. Baillie in 1793. For the knowledge of this fact $I$ am indebted to the Board of Curators of the Royal College of Surgeons, by whose permission, and with the kind assistance of Mr. Clift, I have extracted the following unpublished notes of cases from the Hunterian MSS.

\section{CASE $V$.}

Aneurism of the apex of the left ventricle of the Heart. Sudden death from simple Apoplexy.

General Herbert died suddenly whilst sitting in his chair, April 1757. He was of a full habit of 
body, and had suffered from bad health two years before his death, but had been relieved by bleeding from the nose. He had also been dropsical, and used to complain of a heaviness at the heart; the pulse had been tolerably regular. The dropsical symptoms had subsided before his death. He had never suffered from any symptoms like those of gallstones.

Dissection.-Upon opening the head, the bloodvessels, both arteries and veins, were found very turgid with blood, and nearly a quart escaped from them during the examination. The lateral ventricles were very large and full of water.

Upon opening the pericardium, the apex of the heart was found adherent to it; and upon cutting into the left ventricle, it was found white and callous, and had evidently lost its contractile power. At the apex it was very thin, and had formed into a kind of aneurism, which was lined by a thrombus of its own shape.

The gall-bladder was very large and full of bile, owing to the presence of a large calculus in the commencement of its duct*.

No preparation taken from this case appears to exist in the museum; and the only specimen published in the catalogue, as of this description, is one which exhibits two aneurisms of the base of the left ventricle, the one the size of an orange, the other that of a large nut. Of this preparation (28), which is a very

* Compiled from Hunterian MS. "Account of Dissections of Morbid Bodies." Vol. III. No. 32, p. 20. 
good specimen of the disease, I am sorry to say that I have been unable to find any notes remaining in the Hunterian MSS.

There is, however, a series of preparations arranged in the catalogue under the head of "tumours analogous to aneurism," two of which at least are valuable as illustrating one mode of the early formation of these aneurismal dilatations, and one which I believe I am the first to notice. In No. 360*, we have a portion of a heart described in the catalogue as shewing " an appearance similar to tumour on the inside of the right ventricle. It is composed of a succession of laminæ of coagulated lymph, that seem to be dissolved in the centre into a kind of glairy mucus, which gives it a cavity." No. 361 is " a portion of the apex of a heart, shewing a similar formation in both ventricles." These tumours appear to correspond accurately with the description which Laennec gives of his "globular excrescence of the internal walls of the heart," + and which have alsso been well described by Andral in his excellent chapter " on the lesions of the blood contained in the cavities of the heart." $\ddagger$ In the Hunterian MSS. this form of coagulum is generally spoken of, after the older authors, under the name of "Thrombus."

* Catalogue of Hunterian Collection. Path. Prep. in Spirit. 1830. p. 32.

† De l'Auscultation, \&c., by Forbes. 4,th Ed. 1834. p. 616 .

¥ Path. Anatomy, by Townsend and West. Vol. II. p. 355 . See also Bouillaud Traité Clinique, \&c. T. II. p. 179. He calls them "fibrinous vegetations." 
In the first of these cases, No. 360, the walls of the ventricle (the right) appear perfectly healthy, and this is also the case in the right ventricle of the second preparation, No. 361; but in the latter the apex of the left ventricle, which is the seat of the largest of these tumours, is plainly thinned and hollowed out around it, so as to form an incipient aneurism; which, however, is not sufficiently advanced to produce any external projection or tumour. The substance of the ventricle, however, in this situation, is of a pale colour, and is evidently the seat of fibrous degeneration. The preparation corresponds so accurately with the description in the following case, that I have no hesitation in referring them to each other.

\section{CASE VI.}

Incipient true aneurism of the apex of the left ventricle of the Heart, with hollow globular coagula. Hemorrhagic Pleurisy and Pneumonia. Serous effusion in the Brain.

Dissection of the body of Colonel Graham. The membranes of the brain were loaded with serum, of which there were three or four ounces in the ventricles. Some ossification of the arteries of the pia mater. The substance of the brain was healthy. The pleuræ were adherent over the upper points of the lungs. The left lung was healthy, but a part of the lower lobe of the right lung was dense from its tissue being gorged with water. The posterior part of the pleural cavity of the same side was smeared over with red blood, but without any appearance of ruptured vessels. The substance of the left ventricle of the heart, for about an inch around the apex, was. 
thinner, more flabby, and of a more livid colour than usual; it was occupied by a firm substance like coagulated blood of long standing, the interior of which was hollow, and filled with half coagulated blood. In many places in the interior of this ventricle were a number of small bodies peeping out from between the fasciculi, and which were of the same nature. The external surface of all of them was smooth, and as if washed clean of the red particles of the blood; by the motion of the circulating fluid through the ventricles. Something of the same kind was found in the right ventricle, which shewed the nature of the disease still better than the left *.

The production of the aneurismal dilatation in this case would appear to admit of the following explanation. The thinnest part of the walls of the ventricle was the seat of a foreign body, by which it must have been compressed during the contractions of the heart; as a consequence of this, atrophy of the muscular fibres ensued, then fibro-cellular degeneration, and lastly, the dilatation of the part; the lining membrane of which was most probably in the beginning quite healthy.

The third and last preparation in this series, No. 362, is described in the catalogue as "shewing a similar formation occupying a large portion of the cavity of the left ventricle." The coagulum, however, would appear to be of a different character from that in the last case.

* Compiled from MS. Cit. Vol. III. No. 156. p. 169. See Plate III. Fig. 2. 
The following is the case as compiled from the MS. notes.

\section{CASE VII.}

Aneurismal dilatation of the anterior portion of the left ventricle of the Heart. Apoplexy. Softening of the Brain.

Mr. _- aged 61, died of apoplexy. His death was preceded by vomiting.

Dissection.-A partial softening of the brain was met with, accompanied by a dotted redness of its substance. There was about an ounce and a half of water in the lateral ventricles. Pleuritic adhesions existed on the left side of the chest. Upon cutting into the pericardium I found that it had a glutinous adhesion to the heart on the left side, which was, however, readily separated. The heart appeared to be everywhere sound, except on the fore part of the left ventricle close to the septum, where there was a gentle rising, and a kind of discolouration. Upon exposing the interior of this ventricle, I observed a solid coagulum of blood, of an oval figure, occupying that portion of its cavity corresponding to the external swelling; and this was firmly entangled among the fasciculi of the heart, and was evidently of old standing. Fluctuation was distinguishable beneath this coagulum. I made a section through the external swelling into the coagulum, and found a small cavity occupying partly the wall of the ventricle and partly the substance of the coagulum. This cavity contained a bloody matter. (The muscular substance of the ventricle in the part occupied by the coagulum had 
lost its firmness, and was considerably thinner than elsewhere; at the most convex part of the dilatation not measuring more than two lines in thickness. J. T.) The right cavities of the heart contained some of the ordinary coagula. The stomach was very much contracted*. .

Hunter concluded, with respect to this case, that the heart, in the situation of the coagulum, " had lost its proper action;" or, as he says elsewhere, " must have become paralytic," to have allowed the blood to coagulate in this place. Subsequently to the formation of the coagulum, he believed that an abscess had formed in the substance of the ventricle, the matter of which had come in contact with the coagulum, had dissolved part of it, and in this way had produced the bloody fluid which was met with in the cavity.

Even admitting that an abscess had really existed in this case, which $I$ think neither the description given by Mr. Hunter, nor a careful examination of the preparation will warrant us in concluding, I should be strongly inclined to assign its production to a period prior to that of the coagulum. I should, however, rather suppose that the bloody fluid spoken of was simply some grumous uncoagulated blood, which had become confined between the coagulum and the wall of the ventricle. The case is very interesting, as confirming the view taken of the mode of production of the dilatation in the preceding case.

A case recorded by Corvisart, (5) in his chapter on polypiform concretions, also appears to illustrate

* MS. Cit. Vol. III. No. 122, p. 128. 
this mode of production of an aneurismal dilatation of the walls of the heart*.

In the history of the disease, as it is met with in the left ventricle, which I shall now attempt to give, I shall apply, as rigorously as may be, the numerical method to the fifty-eight cases to which references are given in the Appendix.

Lateral aneurism of the left ventricle is met with under two principal forms. Thus it may be either unattended by any external deformity of the heart, and confined altogether to the ventricular walls; or it may present itself in the form of a tumour growing from the exterior of the organ, and in size varying from that of a nut to that of the heart itself. In sixtyseven aneurisms occurring in the fifty-eight cases, thirtyfive were attended by tumour; in nineteen there was no tumour ; and in the remaining thirteen, it is doubtful whether tumour existed or not; although, from the small size of the sacs in these latter cases, it is probable that the disease scarcely extended beyond the surface of the ventricle. There can scarcely be a doubt, that in its earlier stages at least, this lesion is far from unfrequent ; and it may be observed, that it is in these stages that anatomical examination will be likely to throw light upon the mode of its formation. Sir Astley Cooper has informed me that he has himself met with two or three cases, which I have not included in the Appendix, in which the commencement of the disease existed. The seat of the

*. Diseases of Heart, by Hebb, 1812, Case 56, p. 398. 
lesion in these instances was the anterior wall of the ventricle, the dilated portion was lined with layers of coagula precisely like those met with in the aneurisms of arteries, the pericardium corresponding to it was thickened, and in some of the cases, Sir Astley thinks was adherent.

The size of the aneurismal sacs varies greatly; thus, in nine cases, their size might be compared to that of nuts ; in twenty, to that of walnuts; in seven, to fowls' eggs; in fourteen, to oranges; and in nine cases, $(4,7,10,11,20,24,28,34,48$,) it almost or quite equalled that of the healthy heart itself. In one of these last named cases, that recorded by $\mathrm{Mr}$. Adams, $(20$,$) the tumour had nearly presented exter-$ nally. When the disease has been of some standing, and the sac has attained to a certain size, it usually opens into the ventricle by a mouth, the diameter of which is narrow, relatively to that of the sac itself; and the lips of which, like those of old arterial aneurisms, are generally projecting, well defined, and formed of a dense fibrous tissue. This kind of opening to the sac was present in at least. twenty-five of the cases; whilst, in nineteen others, which were mostly incipient, the mouths were as wide or wider than any other part of the sac, and no such projecting lips existed.

With respect to the tissues of the heart engaged in the formation of the aneurismal sac, a careful analysis of the cases would seem to shew, that in fifteen, the sacs were formed by the muscular fibres and pericardium ; in four, $(25,30,33,44$, ) by the endocardium and pericardium only; in twenty-five, by all of 
the structures entering into the composition of the walls of the heart ; whilst, in twenty-three cases, the disease was either too far advanced, or the data are insufficient to enable us to assign them to their proper places. The aneurismal sacs had in some cases undergone changes and transformations of different kinds; thus in two cases, $(32,37$,) they are stated to have assumed a steatomatous structure; in three, $(4,19,58$, a cartilaginous one; which latter change, in six others, $(7,15,20,36,40,49$,) was combined with a more or less advanced calcareous or osseous degeneration.

In twenty-one cases, and probably in a still greater number, the sac had become strengthened by adhesion to the loose or fibrous layer of the pericardium; and in all these instances, the disease had advanced to theextent of producing tumour on the external surface of the heart. How small an extent of such tumour is capable, by its attrition on the opposed surface of the pericardium, of originating the limited inflammation which terminates in this adhesion, is well shewn by the Hunterian case, which forms the seventh related in this paper, (52,) and also by a preparation in the museum of St. Bartholomew's Hospital (30); in neither of which does the tumour form more than a gentle prominence on the surface of the heart. In a few cases, $(2,33,55$, ) this process had not extended beyond the production of opacity and thickening, or that of shaggy false membranes over the surface of the sac.

In six cases, $(1,9,16,22,55,57)$ in none of which had adhesion taken place between the aneurismal portion of the heart and the pericardium, and 
in which the aneurism scarcely, if at all, projected beyond the surface of the ventricle, a rupture of the sac had occurred, which had led to a fatal extravasation of blood, into the pericardium. In one case only, related by Sir Astley Cooper, (10,) does rupture appear to have occurred when there was the adhesion alluded to, and in this instance the left pleura was the seat of the hæmorrhage. In another instance, $(\mathbf{3 4}$, ) the tendinous centre of the diaphragm was adherent to the greater part of the sac, which was very large, and had a small supplementary pouch, with very thin walls engrafted upon it; and had this become the seat of a rupture, it must have led to extravasation into the peritoneum.

As regards the contents of the sacs, in twenty-three cases, which were chiefly those furnished with constricted mouths, and which were of considerable size, there was found a greater or less quantity of laminated coagula ; seventeen, either apparently of less standing, or situated more in the direct channel of the blood,contained simple amorphous coagula; whilst nineteen appear to have been found empty after death. In three other cases, the contents were, in one, $(51$,$) a$ hollow globular coagulum; in two others, $(5,52$, simple fibrinous ones, evidently of old date.

It would appear that no part of the left ventricle is exempt from becoming the seat of aneurism. Although a more extended acquaintance with cases than was possessed by $M$. Breschet at the time when he wrote on this subject, shews that this author was in error when he supposed the disease to be nearly, if not quite confined to the apex of the ventricle, yet 
this would still appear to be its most frequent situation. Thus the sixty-seven aneurisms which occurred in the fifty-eight cases, omitting one case (21) in which this is not mentioned, may, as regards situation, be thus distributed; at or near the apex of the ventricle, twenty-seven ; in different points of the base, twentyone; in intermediate portions of the lateral walls, fifteen; in the interventricular septum, three. Of the cases in which the sac was seated at the base, four, which occurred to Dr. Hope, (31, 32, 36, 37, ) are remarkablefrom having opened both into the ventricle and into the aorta. Dr. Hope is of opinion that "steatomatous degeneration had caused the formation of a canal from the aorta underneath one of the sigmoid valves and the internal membrane of the left ventricle," and that, in this way, an aneurism had originated, which had ultimately opened into the cavity of the heart. It would, however, appear to me more probable, that the aneurisms had originally been formed in the ventricle, and had subsequently communicated with the aorta, as a consequence of the coexistent disease of the valves of that vessel; and I may observe, that this view would appear to be supported by four other cases $(16,22,43,56$,$) in which the sacs had precisely$ the same situation, but in which there was no communication with the aorta. In the last of these cases, the preparation of which is in the museum at St. Bartholomew's Hospital, the contiguity of the aneurism to the aorta is such as to have led to its being described in the MS. catalogue as an aneurism of that vessel. Of the three cases $(5,12,42)$ in which the aneurism had its seat in the septum of the ventricles, one 
is only briefly alluded to by M. Cruveilhier as occupying its lower half, and as threatening to burst into the right ventricle. In another of these cases, recorded by Laennec, an accidental ulcerated canal had been formed in the highest part of the septum, and was accompanied by what would appear to have been a minute aneurism, containing fibrinous coagula. It is well known to anatomists, that the highest part of the septum, which occupies the angle between the posterior and right aortic valves, and which, in some instances of congenital malformation, is deficient, is in the human subject formed not of muscular fibres, but simply of the endocardium of the right and left ventricles almost in apposition, and strengthened only by the interposition of a little fibrous tissue continuous with that of the aorta. In many ruminant animals this point is well secured by an osseous plate; but in man, as a comparatively weak spot, it is perhaps probable that occasionally it may become the seat of aneurismal dilatation. I am not, however, in possession of any fact which proves this to have occurred; unless a case, the preparation of which is in the museum of the Royal College of Surgeons, and which I shall describe when speaking of aneurismal dilatation of the valves of the heart, is to be considered of this nature. To conclude these observations on the situation of aneurism of the left ventricle, the only general conclusion that we can come to appears to be, that the thinnest parts of its walls, or the apex and the highest part of the base, are those which are much more frequently than any others the seat of the disease.

In general, or in fifty-two out of the fifty-eight cases, 
only one aneurism existed in each; but in four cases $(23,27,29,55)$ two were met with in each ; in one (47) there were three; and in another (45) four incipient aneurisms. In two instances, $(25,47$,) it is not improbable that two sacs which were originally distinct had coalesced, so as to form a single aneurism; and in another case, $(38$,$) three sacs appear to have$ united in this way.

An important point in the history of lateral aneurism of the heart, is that which relates to the other lesions of this organ, which are found to accompany it. To begin with the pericardium: in addition to the twenty cases already alluded to in which there was adhesion to the surface of the aneurismal tumour, we find that, in seven cases, $(13,20,25,58,45$, 46, 47,) there was general adhesion of this membrane to the surface of the heart; that in one, (39,) there was recent hæmorrhagic pericarditis; and that in three, $(21,44,49$,$) there was dropsy$ of this cavity. In twelve cases, the endocardium is stated to have undergone different changes of structure ; so as to have become either white, opaque, or thickened in the immediate neighbourhood of the sacs, or even more extensively ; and in one case, (54,) there was a minute deposit of calcareous matter either in or beneath this membrane. The muscular substance of the ventricle was, in at the least nine cases, the seat of more or less extensive fibro-cellular degeneration, which was generally most marked around the sacs; in one case, (47,) there was a cartilaginous transformation ; and in another, $(7$,$) induration from a non-$ 
specified cause. In one instance, (27,) the walls of the ventricles are said to have been the seat of "lardaceous tumours," and in another, (54,) of extensively diffused suppuration. In numerous cases, there was a marked atrophy either of the fleshy columns which form the pillars of the mitral valve, or of the smaller ones which constitute the net-work on the internal surface of the ventricle. The valves of the left cavities are stated to have been diseased in ten cases; in five of these the mitral valve was the seat of the lesion, and was constricted by cartilaginous or osseous deposit ; in three, the aortic valves were diseased, and both these sets of valves were implicated in one example. In eight cases, the valves are reported to have been healthy; whilst, in the remainder, their condition is not mentioned.

Respecting the pathological changes in the heart, which we have thus seen to accompany lateral aneurism of that organ, it appears important to observe that they may almost universally be regarded as the effects of inflammation. With respect to a majority of them, or those seated in the muscular tissue and pericardium, there can, on this head, scarcely be a doubt; and although some difference of opinion may still exist respecting the alterations which have been alluded to as involving the endocardium and the valves, yet they are now very generally, and I think correctly, regarded as the consequences of inflammation. From this part of our enquiry also, I think we can scarcely avoid drawing the inference, that aneurism of the heart cannot be regarded as exclusively 
dependent upon pathological changes in one only of the tissues entering into the composition of this organ.

There is another class of pathological conditions, which are not unfrequently found to accompany aneurism of the heart, to which it is necessary to allude; more especially as one of them has, by M. Breschet, been regarded as playing an important part in its production. I allude to changes in the thickness of the walls, and in the capacity of the cavities of the heart; and particularly to hypertrophy and dilatation.

In the fifty-seven cases of aneurism, there is reported to have been general dilatation of the organ in three instances; dilatation with hypertrophy of all the cavities in three; dilatation with hypertrophy of the left ventricle in nine; simple dilatation of the left ventricle in four; and simple hypertrophy of the same cavity in two other cases.

The number of cases in which the heart is not stated to have been the subject of some lesion in addition to the aneurism, does not exceed ten; and in three only $(17,48,52)$ is it positively stated to have been otherwise healthy.

Before entering into the consideration of the nature of the disease and of its mode of production, it will be desirable to notice what may be ascertained respecting its causes. In the first place, as respects the influence of sex; in forty cases, in which this is recorded, thirty occurred in males, and ten in females. The proportion thus met with in the female, is much greater than is found to be the case 
in arterial aneurisms, which, according to Hodgson; occur eight, and according to Lisfranc, eleven times oftener in the male than in the female. Even as respects aneurism of the aorta, the most common variety of the disease in the female, Dr. Hope has only found the proportion to be rather larger than that indicated by Hodgson.

The age of the patient is either stated or to be inferred with tolerable accuracy in thirty-five cases. The youngest patient appears to have been eighteen and the oldest eighty-one years of age ; and the whole of the cases may be arranged in decennial periods as follow :-

Under ......21 years of age; 1 case.

From 21 to 30 ............. 9 cases.

$31 \ldots 40 \ldots \ldots \ldots \ldots . .4 \ldots .$.

$41 \ldots 50 \ldots \ldots \ldots \ldots . . . . . .6$

$51 \ldots 60 \ldots \ldots \ldots \ldots 6 . \ldots .6$

$61 \ldots 70 \ldots \ldots \ldots \ldots . \ldots . . .$.

$71 \ldots 80 \ldots \ldots . \ldots . . .7 \ldots .$.

Above $80 \ldots \ldots \ldots \ldots \ldots \ldots 1$ case.

From this analysis, then, it appears, that after adult age, cardiac aneurism is not remarkably confined to any particular period; although it would seem to prevail with the greatest frequency at two distinct periods, or between the ages of twenty and thirty, and again in very advanced life. In this respect, then, we likewise find that cardiac aneurism differs remarkably from arterial, which, according to the experience of Sir 
Astley Cooper, and also from an analysis of 108 cases by M. Bizot*, prevails chiefly between the ages of thirty and fifty.

As regards the occupation and mode of life, out of seventeen cases, all males, in which this is stated, it appears that there were one nobleman, $(1$,$) one mer-$ chant, $(2$,$) one tragedian, the celebrated Talma, (17,)$ two generals, $(16,50$,) one colonel, $(51$,$) five private$ soldiers, $(10,18,24,35,39$,) one gondolier, $(8$,$) one$ cabinet-maker, $(47$,$) two tailors, (31,49$,$) and two$ victuallers. $(33,48$.) It is a striking fact, that out of this number, eight, or one half, should have been soldiers; a circumstance which would lead one to suspect that the exposure to which this class of persons is subject, and the forced exercise which they undergo, may have something to do with the production of this lesion.

With respect to the causes, predisposing and exciting, of cardiac aneurism, very little that is satisfactory appears in the cases hitherto published. Under the head of predisposing causes may perhaps be placed intemperate habits, which are mentioned in four cases, (20, 31, 44, 47,) and rheumatic disease of the heart in two cases. $(27,47$.$) Although$ not mentioned, it is still highly probable, that, in some at least of the six other cases, in which universal adhesion of the pericardium was met with, rheumatic pericarditis had existed; and there can scarcely be a doubt, that, as of other organic diseases of the heart,

* Mém. de la Soc. Méd. d'Obs. Tom. I. p. 409. Recherches sur le Cour et le Système Artériel. 
so also of aneurism,-acute rheumatism, affecting this organ, either in the form of endocarditis or of pericarditis, is to be regarded as closely connected with the production, if not as the efficient cause, of this lesion.

If this view should prove to be correct, we shall have no difficulty in explaining the greater frequency of cardiac than of arterial aneurism during early life; as it is well known, that in the progress of acute rheumatism, the inflammatory affections of the heart which have been alluded to, occur much oftener at this than at any other period.

The exciting cause of the disease would appear to have been external violence in the form of an injury of the chest in the case of the gondolier, $(7$,$) a fit of$ violent anger in that of the nobleman, $(1$,$) protracted$ mental anxiety in another instance, $(33$,) severe efforts on the stage in the character of Hamlet, in the case of Talma, (17,) and in a fifth instance, (10,) the retention of the breath during a military flogging.

From an examination, then, of the anatomical details, as well as of the apparent causes of the disease, in reference to the determining of its nature, I come to the conclusion, that in twenty-two cases out of the fiftyeight, the aneurism originated in a dilatation of all the structures entering into the composition of the walls of the heart ; and in six, $(1,8,9,12,17,26$, ) in a solution of continuity of the lining membrane and inner stratum of muscular fibres, either as a consequence of ulceration, or, what is more probable, of rupture; whilst, in the remaining thirty cases, the disease was either too far advanced, or the data given 
are insufficient to enable us to form a satisfactory opinion on this question.

I therefore conclude that this lesion, in by far the greater proportion of cases, is of the nature of true aneurism; or that it has its origin in the dilatation of a portion of the walls of the heart, which has become less able to resist the distending force of the blood during the ventricular systole, in consequence of organic changes in the tissues composing it. These changes may be confined to one of these tissues, as the endocardium; or they may involve that membrane and the muscular structure simultaneously; or, lastly, they may, I believe, originate in the pericardium, and be propagated from without inwards. In a great majority of instances, these changes would appear to have been the result of a more or less active antecedent inflammation.

I have on one or two occasions noticed an appearance on the internal surface of the left ventricle, which appears to me to have been the earliest stage of those pathological changes which terminate in the formation of true aneurism. This consists in a more or less decided enlargement of one of the natural interspaces or depressions between the smaller fleshy columns. In one case which I have had a recent opportunity of examining, I met with a small cavity in the centre of the interventricular septum, which was capable of containing a small horse-bean. This cavity was evidently an enlargement of one of the natural sulci, which have been alluded to; it was traversed by the lining membrane of the heart, which 
in this particular spot was white and opaque, and it was only separated from the cavity of the right ventricle by a very thin stratum of muscular fibres, of a whitish appearance and dense fibrous texture. (See Plate III., fig. 1.)

Granting that the condition which has been now described, would, under certain circumstances, have led to the production of an aneurism of the heart; or, in other words, that it constituted an aneurism in its earliest stage, the observation must be regarded as important, and as fully confirming the view which has been advocated of the more usual mode of formation of true cardiac aneurism.

The cases of biloculate and multiloculate aneurisms, a few of which are on record, $(25,38,47$, ) as well as the at first sight anomalous case described and figured by Dr. Elliotson, (27,) in which two distinct aneurisms communicated by a very small opening,are all, I think, susceptible of explanation, upon the view of aneurisms having originated in the dilatation of two or more adjoining depressions, formed by the interlacement of these muscular bundles.

From two cases reported in this paper, as well as from another published by Corvisart, $(5,51,52$, ) it would appear probable, that a lesion of the blood contained in the ventricle, leading to its spontaneous coagulation, is adequate to the production of an aneurismal dilatation; independently of any original morbid condition of the walls of the cavity. (See plate III., fig. 2, and likewise pp. 214, 216).

True aneurism of the heart, with a few rare ex- 
ceptions, which will be hereafter alluded to, is analogous to the circumscribed, lateral, or sacciform true aneurism of arteries. In the early stages of this form of aneurism of the heart, the disease may properly be spoken of as aneurismal dilatation of the heart.

The occasional occurrence, however, of false aneurism of the heart is, I think, not to be doubted. That partial ruptures of the heart may occur, is sufficiently proved by cases in which such have been observed, in addition to others which have been complete, and have hence occasioned death. Again; the examination of some cases and preparations would lead us to conclude that rupture of the heart,' even when ultimately fatal, has not always been of momentary occurrence, but, on the contrary, has taken place very gradually, having commenced in the internal stratum of fibres, and only slowly spread to the external. Thus, in the museum of University College, there are two preparations of ruptured heart, (599 and 600, ix. M. B.,) both from subjects in the dissecting room, and which $I$ have been informed by Mr. Alexander Shaw were taken from the cases which have been referred to by the late Mr. John Shaw, in his " Manual of Anatomy." * The rupture in both of these specimens is extremely small, and in the one is seated at the apex, in the other, midway between the apex and base of the left ventricle; and in both the perforation would appear to have been consequent upon a previous imperfect rupture : for internally there is a destruc- 
tion of the muscular substance, to an extent capable of holding in the one case a nut, and in the other a walnut, around the margins of which the ruptured lining membrane and muscular fibres are very evident. We have only to suppose, that under a favourable combination of circumstances, the extension of the rupture had in these cases not taken place, when we may easily perceive that a false consecutive aneurism would have been produced.

It may also be observed, that this view is further supported by the sudden occurrence of the first symptoms of the disease in a few of the cases, $(1,7,10$, 17,) under circumstances not unlikely to produce rupture of the heart, and of a character almost identical with those attributed to that lesion.

Although I am not at all disposed to deny the possibility of false aneurism of the heart originating in ulceration, and in the discharge of the contents of abscesses and cysts into the cavity of the ventricle; yet I may observe, that I am not satisfied of this having been the mode of production in any case with which I am acquainted:

It is well known that "external mixed aneurism," or the supervention of a false upon a true aneurism, does not occur in the pericardial portion of the aorta, in consequence of the absence of a distensible cellular coat to this portion of the artery, and that hence lateral aneurism in this situation usually proves fatal from rupture at an early period. For the same reason, mixed aneurism does not occur in the heart, but as we have already seen, the aneurismal sac usually soon gains 
an adhesion to the pericardium, by which means rupture is, in most cases, prevented.

True aneurism, or that by dilatation, may either involve a limited point only, or the whole circumference of an artery; and in the latter case it constitutes a disease which has been variously named, " preternatural dilatation," " cylindrical or fusiform aneurism," " diffused true aneurism," and " arteriectasy." * I am, I believe, the first to contend for the existence of an analogous form of aneurismal dilatation in the heart; for, as I have observed when speaking particularly of the fourth case in this paper, the lesion in that instance would appear to merit the name of "diffused true aneurism of the heart." Dr. Carswell and M. Cruveilhier have indeed each alluded to a case of extensively diffused true aneurism of the heart, $(39,46$,$) and the former has given a$ drawing of the disease, but in neither of these cases had the dilatation involved the entire circumference of the ventricle.

It appears not improper to designate by the name of dissecting aneurism of the heart, that form of the disease, in which an aneurism, as in Dr. Hope's cases, $(31,32,36,37$,$) forms a canal under the lining mem-$ brane of the ventricle, which opens at some other point. The analogy of these to the rare cases of arterial aneurism, reported by Laennec, Guthrie, and Shekelton, would appear to be sufficiently obvious.

* The "arterial varix" of Dupuytren, or " cirsoid aneurism" of M. Breschet, may properly enough be regarded as a variety of diffused true aneurism. 
M. Bouillaud * has drawn a parallel, and I think justly, between the case of M. Reynaud, $(23$,$) in$ which, as in some others which I have examined, $(30$, 44,) the sac is formed solely by the endocardium and pericardium, with that rare form of arterial aneurism, described by Haller, Dubois, and Dupuytren, and still more recently by $M$. Breschet, in which the lining membrane of the vessel protrudes through a rupture in the middle tunic, constituting a lesion, which has been sometimes designated "aneurisma herniosum," and sometimes " internal mixed aneurism."

The hernia-like protrusion of the lining membrane through the muscular substance of the ventricle, in the shape of an aneurismal sac, is particularly well seen in Mr. Langstaff's case, (44,) which has already been particularly described in this paper.

In the case of an aneurism seated in the interventricular septum becoming ruptured, so as to form a communication with a portion of the venous system, -the right ventricle, we should have a lesion produced altogether analogous to that which results from the wound of an artery and its accompanying vein, and to which the name of spontaneous varicose aneurism of the heart, is perfectly applicable. We possibly have an instance of such a form of the disease in the case related by Laennec, (12,) and another alluded to by Cruveilhier, (46,) approached very closely to it.

We are then, I think, justified in asserting that,

* Dict. de Méd, et Chir. Prat. Article Aneurism. 
we find in the heart, with the exception of " the external mixed aneurism," for the non-occurrence of which there is an anatomical cause, all the varieties of the disease which are met with in the arteries themselves; and that we cannot recognize the simple increase in the capacity of the cavities of this organ as constituting a lesion that ought to be spoken of as aneurism.

In the departments of symptomatology and diagnosis, the information that we possess relative to this form of disease is less extensive and precise than that relative to its pathology. It is probable that, in its incipient forms, aneurism of the heart is not necessarily attended by any derangement in the function of this organ. In two casés, $(16,23$,$) it is expressly$ stated that no symptoms referrible to the heart existed during life, and in these the disease was in a very early stage.

The mode of incursion of the disease differs remarkably in two classes of cases. Thus in three instances ( 1 , $10,17)$ the attack was sudden, and attended with marked symptoms, analogous to those observed in cases of rupture of the heart, when this is not directly fatal; either in consequence of the rupture being incomplete, or from the opening being so small as to allow only of a very gradual effusion of blood into the pericardium. The most instructive of these cases is that of the nobleman, $(1$,$) related by Galeati; who$ after a violent fit of anger, was suddenly seized with severe præcordial pain, orthopnœea, agitation, fear of death, a disposition to syncope, and a vibratory, frequent but languid pulse. 
In cases of this description, the mode of attack, as well as the immediate causes, would lead us to conclude that the disease is of the nature of false aneurism from rupture.

In the great majority of cases, however, the disease would seem to have had a very insidious origin, and to have been only very gradually announced by symptoms. This is what we should be prepared to expect in cases of true aneurism; and it may be observed that this difference in the mode of attack in the two forms of the disease, corresponds with, and supports the conclusion, which chiefly on anatomical grounds, has been already come to, that true aneurism of the heart is much more common than false.

In five cases, $(5,14,32,36,38$, ) the symptoms of the disease are described generically as those of " diseased heart." In twenty-three cases in which the symptoms are given in detail, these, taken in the order of their frequency, were as follow ; dyspnœa, in several instances amounting to the severest form of orthopnca, in fifteen cases ; præcordial pain of different characters, in one or two cases amounting merely to uneasiness, but in several others accompanied by a sense of weight, in fourteen ; dropsy more or less extensive, in ten cases; palpitation in nine cases ; anxiety, dread of death; or restlessness, in eight; and syncope, or a disposition to it, in three cases.

In addition to these symptoms others are also more rarely mentioned; such as cough, throbbing of the carotid arteries, pulsation of the jugular veins, livid or blue countenance, and hæmorrhage from the nose 
and lungs. The condition of the pulse is noted only in a few of the cases, and in seven of these it is stated to have been feeble, sometimes in an extreme degree.

Of the duration of the symptoms referrible to the heart, I find notices in fourteen cases. In one remarkable case, that of the nobleman, already more than once alluded to, $(1$,$) the patient would not ap-$ pear to have survived more than ten days after the development of the lesion. In the other cases the length of time occupied by the disease appears to have varied from three or four months (47) to fifteen years (7).

In twenty-four cases, the mode of death is stated. In twelve of these in which it was very sudden, it arose, in three from syncope $(7,26,48)$; in one from an unknown cause (21); and in eight from internal hæmorrhage. In six of these eight cases, $(1,9,16$, $22,55,57$,) the hæmorrhage was dependent upon a rupture of the aneurismal sac into the pericardium; in one, $(10$,$) upon a rupture of the sac into the left$ pleura; and in another (8) upon a rupture of the substance of the ventricle itself, in the immediate neighbourhood of the sac. In four cases $(18,43$, $50,52)$ the patients appear to have died from an apoplectic or paralytic affection, and in one (4) from epistaxis. In three cases $(33,34,47)$ the mode of death was the more ordinary one in heart affections, or that by apnoea, (asphyxia,) and this, though not positively stated, was probably also the case in six other instances $(10,14,20,31,44,49)$. In the following cases, 
six in number, $(15,17,23,38,39,51$,$) as well as$ in the four apoplectic cases, death was evidently the result of complication with other diseases.

As aneurism of the heart has seldom been met with, uncomplicated with other lesions of this organ, great difficulty necessarily attends our forming any conclusions as to the general symptoms, if any, which distinguish it. Although, however, thesymptoms which have been met with cannot be regarded as pathognomic, yet their rationale does not appear at all obscure. The presence of an aneurismal dilatation of the walls of the heart, attended as that often is by fibrous degeneration and other changes in the tissues forming them, must almost necessarily lead to the imperfect contraction of this muscle, and to the consequent retardation of the blood in its cavities; thus producing symptoms of obstruction in the arrière circulation; dyspnœa, venous congestion, passive hæmorrhages and dropsy. In some cases, however, it is probable that, from the heart retaining a tolerable share of vigour, and from its walls, unaffected by any other morbid change, becoming the seat of a moderate degree of hypertrophy, the disposition to a retardation of the blood may as it were be counterbalanced; and that the development of the symptoms of an obstructed circulation may, for a considerable period, be postponed. On the other hand, these symptoms may be much increased in severity, where there is not this degree of tone in the muscular fibres, by the supervention upon the primary affection of a general dilatation of the ventricle. 
But in addition to the class of symptoms now alluded to, a variety of distressing sensations in the præcordial region were experienced in a great proportion of cases ; which would, to a certain extent, serve to distinguish the disease from cases of simple dilatation with or without hypertrophy. Symptoms of this description are met with in two well known forms of disease of the heart, angina pectoris and valvular disease, and especially in those cases in which there is much ossification. Now although the group of symptoms which are known by the name of angina pectoris, cannot always be referred to an ossified and indurated condition of the coronary arteries, valves, and origins of the great vessels, yet as the best recent authorities concur in the belief that, in the majority of cases, it is associated with these or similar changes, we shall not perhaps be generalizing too rapidly, in ascribing the uneasy sensations and pain, which are met with in these three forms of disease, to one common cause.

This would appear to me to consist in the irritation occasioned by the rigid and inelastic morbid structures to the cardiac nerves, and especially to those derived from the great pneumogastric,-a nerve which recent experimental researches, and especially those of M. Brachet, as well as anatomical analogy, have shewn to be, to a certain extent, in all probability, a sentient nerve. The character of the pain experienced in aneurism of the heart differs, as we have seen, in different cases, but in some it was described as being accompanied by a peculiar and distressing sense of 
weight; a kind of pain more intense, but still very similar to that often complained of in aneurism of the thoracic aorta.

The diagnosis of aneurism of the heart must, in the present state of our knowledge, necessarily remain very doubtful. As Dr. Elliotson has observed, "the general symptoms which occur may well be supposed, by those who know the value of auscultation, to leave the nature of the disease in doubt." ${ }^{*}$ Indeed, it is not to be expected that a diagnosis will ever be effected, without the aid of the information to be derived from an acoustic and manual examination. Unfortunately, the cases in which the physical signs have been observed are very few in number. In three cases, $(18,27,31$, ) the impulse of the left ventricle is stated to have been increased; in one, $(34$, ) the action of the heart generally was forcible and tumultuous ; and in two others, $(33,39$, feeble and obscure. In four cases, $(18,31,36,37$, ) a bellows or rasping sound was heard with the ventricular systole; and in a fifth case, (47,) a similar sound was heard to the left of the sternum. In one case, (33,) the character of the first sound was short, like that of the second.

The following communication, with which I have been favoured by Dr. C. J. B. Williams, relieves me from the necessity of offering many observations of my own on the physical diagnosis of this lesion. Any views entertained by so distinguished an auscultator cannot fail to be received with the attention which they so justly merit, and I feel myself particularly

- Diseases of the Heart, 1830, p. 28. 
happy in being the medium of his communicating them to the profession.

“ MY DEAR SIR,

"I do not find that I have notes of any cases of partial aneurism of the heart which furnished physical signs distinctive of this affection. In fact, the partial dilatations were inconsiderable, and discovered only after death.

"The only peculiar set of signs, that I can conceive to mark this affection, would be a pulsating tumour, felt between the ribs; with dulness on percussion, boyond the usual limits; perhaps with some displacement of the heart. The sound heard at the pulsating spot would probably be a short loud one with the systole of the ventricles, (provided that systole be strong,) perhaps accompanied with a whizzing, if the sac were elastic and its neck narrow. Such a set of signs could only be presented where the aneurism is large; and to distinguish it from aneurism of the descending aorta, it would be necessary to observe that its impulse does not follow, but accompanies the first sound of the heart, as heard at the sternum, and that there is no unusual pulsation or grating sound to the left of the dorsal spine.

"According to its position, partial aneurism of the heart may produce various other signs, but of no distinguishing character. Thus, when at the apex of the heart, or in the neighbourhood of the columnæe carneæ, it could scarcely fail to derange the nicely adjusted function of the mitral valve; and the conse-

voL. XXI. 
quent regurgitation through the left auriculo-ventricular orifice would (where the ventricular systole is strong) be manifested by a blowing murmur below the left mammilla, less distinct at the sternum and in the carotids. Again, when near the aortic orifice, it might dilate this aperture, and render the semilunar valves insufficient to close it : hence a whizzing, grating, or cooing murmur with or instead of the second sound. If the aneurism extends to the root of these valves, and opens a false passage into the aorta, there would probably be a double or to-and-fro murmur, of a grating or whizzing character, heard both at the sternum and in the carotids, occasioned by the forcible flux and reflux of the blood at the ventricular systole and diastole, through the irregular opening.

"I doubt that the sac itself would be likely to become the seat of any other sound than that of the shock from its sudden tension at each ventricular systole. A dilatable sac with a narrow neck might, however, as in the case of arterial aneurism, give a to-and-fro whizzing; but I question whether partial aneurisms of the heart be of that character.

"You see that I speak from principles rather than from experience in this particular lesion. They seldom fail in the simpler forms of disease; but in those more complicated, they become involved with the $x, y, z$ properties of the subject, and elude our analytic powers.

$$
\begin{aligned}
& \text { "Yours, very faithfully, } \\
& \text { "C. J. B. Wilciams. }
\end{aligned}
$$

"Half-moon Street, Oct. 20, 1837." 
The lesion with which I think aneurism of the heart would be the most likely to be confounded, is an aneurism of the ascending aorta either directly above the valves, or of one of the sinuses of Valsalva themselves. In cases of this kind, I think there is reason for suspecting that the impulse and murmur would be present not only after but during the ventricular systole, so that the ground of distinction between cardiac and aortic aneurism, which is laid down by Dr. Williams, would be wanting. Indeed, aortic aneurisms, in this situation, from their proximity to the heart, into the substance and cavities of which they are apt to burrow and even become ruptured, would be likely to give rise to a group of signs almost identical with those of cardiac aneurism*.

The signs of a spontaneous varicose aneurism of the heart, would of course be analogous to those of a congenital perforation of the interventricular septum; and, like that lesion, would in an otherwise healthy and well formed subject, give rise to an admixture of the arterial with the venous blood; but in case of there being an impediment to the pulmonary circulation, or in that of the right ventricle acquiring greater power than the left, the opposite form of admixture, or that of the venous with the arterial blood, would ensue with its usual consequence-cyanosis.

The sound which would be heard in a case of this

* In a case of aortic aneurism which opened into the right ventricle, under Dr. Roe, in the Westminster Hospital, I at first concluded, from the rational and physical signs, that an aneurism of the left auricle was present. 
description would, I have little doubt, be a blowing or rasping murmur with the ventricular systole, and much louder than any that would be likely to be met with in cases of simple aneurism of the heart.

So far as our knowledge of this affection at present extends, we cannot but regard its prognosis as being of the worst description, and even more fatal than that of the internal aneurism of arteries; in which there is a much greater tendency to a spontaneous cure than appears to be the case in aneurism of the heart. In giving an opinion in a case of this kind, it will be very important to bear in mind the great frequency of a suddenly fatal termination.

The treatment of this disease does not appear to offer any peculiar indications. A judicious combination, as far as practicable, of that which is appropriate to dilatation of the heart, with that which is recommended in aortic aneurism, with the view of producing obliteration of the sac, would probably be the most advantageous. As far as experience at present goes, we find that in five instances in which the effects of remedies are noticed, relief was afforded by an antiphlogistic form of treatment, of which in four cases bleeding formed a part. In no disease of the heart, probably, ought stimuli of all kinds, moral and physical, to be more strictly avoided than in this.

\section{ANEURISM OF THE AURICLES.}

The number of cases of aneurismal dilatation which are recorded as having occurred in the left auricle, is much less than that which we have seen to be the 
case in the ventricle. The disease would appear, from the preparations which I have inspected, and the cases which have been recorded, to have been nearly uniformly of the diffused kind, and to have generally involved the entire sinus of the auriele. (B. 2, 3, 4, 6, 7, 8, 9*)

The dilated walls of the cavity are often thickened, and the seat of fibro-cellular degeneration. The lining membrane is opaque, rough, and otherwise diseased, and in some cases even ossified, $(3,4$,$) and is$ lined with fibrinous layers, very similar to those met with in arterial aneurisms. In all these cases, the lining membrane appears to have been continued into the interior of the dilated portion, which consequently merits the name of true aneurism. Occasionally, $(5,-11$, ) the dilatation is confined to the auricular appendage, which becomes excessively distended with lamellated concretions.

In all the cases with which I am acquainted, answering to this description, whether occurring in the sinus or appendage of the auricle, and which are nine in number, the disease was connected with, and appears to have been dependent upon, an extreme contraction of the mitral orifice, producing a difficult transmission of the blood from the left auricle. As the contraction of the mitral orifice is one of the most common lesions of the heart, I cannot but incline to the opinion that many of the cases, which have been reported as exhibiting a simple dilatation of the left

* The references in this division of the paper, relating to aneurisms of the auricle, are to Appendix B. 
auricle in connexion with it, were really cases of aneurismal dilatation.

Through the kindness of Mr. Stanley, I am enabled to submit to the Society a drawing exhibiting the disease in one of these cases, the preparation of which is preserved in the museum of St. Bartholomew's Hospital. (7.) This specimen has already been alluded to by Dr. Latham, in reference to the diseased condition of the auricle, to which, however, he has not applied the name of aneurism*. It has likewise been adverted to by Dr. G. Burrows, in his Croonian Lectures on the pathology of the blood $\uparrow$.

In one case only with which I am acquainted, was the aneurism of that circumscribed kind to which the term lateral or sacculated could be applied. In this case, (10,) there was a sac as big as a nut hanging over the base of the left ventricle, and containing dense fibrinous concretions and liquid blood, which communicated with the cavity of the auricle by a canaliculated pedicle an inch in length.

The case related by Penada $\ddagger$, which has been cited by Dezeimeris and Ollivier asone of aneurism of the left auricle, was, I incline to think, after an examination of it and of the accompanying engraving, merely an instance of ulceration.

* Medical Gazette, Vol. III. p. 118.

$\uparrow$ Medical Gazette, Vol. XVI. p. 650.

$\ddagger$ Mem. di Mat. e Fisic. del Soc. Ital. Tom. XI. p. 545. 


\section{CASE VIII.}

Aneurismal dilatation of the left auricular appendage; great constriction of the mitral orifice; adherent and ossified pericardium.

John B-, aged fifty-four, had suffered from palpitation of the heart, cough, and difficulty of breathing during four years and a half; his symptoms had always been increased by the least exertion, and relieved by occasional depletion from the arm. He had been addicted to excessive drinking. When Mr. Langstaff saw him, the pulse was ninety-nine, very small, and constantly irregular; the countenance was expressive of great anxiety; the lips blue ; the feet and legs œdematous. He died suddenly, five months after coming under Mr. Langstaff's care.

Dissection.-Fluid was found in the abdominal cavity. The liver very firm; its blood-vessels small, and peritoneal covering thickened. The spleen large, its capsule thickened, and partly cartilaginous. There were upwards of four pints of serum in the right pleura, and two pints in the left. The lungs were highly œdematous, and the bronchial tubes loaded with bloody mucus.

The heart was very large, and the pericardium universally adherent. On several parts of the reflected pericardium there were large patches of osseous matter. The auricles were enormously distended with very dark blood. The right auriculo-ventricular opening was constricted, but the left much more so, and the margins of the mitral valve were very much 
thickened. In the left auricle, an aneurism by dilatation had formed in the appendage, it being very much enlarged, and filled with layers of coagulum. The left ventricle was very large; the sigmoid valves healthy; the aorta small.

The description of the disease as it exists in the heart, I have taken from an examination of the preparation, (No. 1449,) which has been deposited in the museum of the Royal College of Surgeons. I mention this, as it differs somewhat from the account furnished me by Mr. Langstaff, and also from that of 'Dr. Thomas Davies, in a short notice which he has given of the same case.

But it is not in cases of contracted mitral orifice only that the left auricle is liable to become the seat of aneurismal dilatation, as a case which was communicated to Dionis shows (1). A soldier who had deserted, whilst in fear of pursuit, struck the left side of his chest forcibly against a tree, by which he was thrown from his horse. From this time he became the subject of severe pain, palpitation, and dyspnœa; and a large pulsating tumour gradually formed to the left of the sternum, which at last extended from the clavicle to the fifth rib. He died about a year after the accident. In addition to ununited fracture of the first four true ribs, empyema, and abscesses in the lungs; the left auricle of the heart was found of immense size, giving rise to the external tumour. The pleura, or probably rather the pericardium, adhered closely to the enlarged auricle, the walls of which were an inch thick, of a 
dense cartilaginous structure internally, and full of grumous blood. The aorta, venæ cavæ, and pulmonary artery and veins were healthy.

Whether the aneurismal dilatation of the auricle, which in this case was consecutive to external violence, originated in an imperfect rupture of the coats of the auricle, or whether it depended simply upon the consequences of the inflammation set up in those coats, I shall not pretend to determine.

In conformity with the views expressed in a preceding part of this paper, relative to the distinction which exists between the diseases of the right and left sides of the heart, I ought not, perhaps, in this place, to treat of dilatation of the right auricle. As, however, casting further light upon some of the causes of this lesion generally, I have briefly alluded in the appendix, to two or three cases $\left({ }^{*} 1,{ }^{*} 2, * 3\right)$ in which the right auricle was the seat of a lesion analogous in many respects to aneurism of the left auricle.

The most remarkable of these appears to be the case of the captain of a vessel, also related by Dionis, (*2) who, after making powerful efforts to restrain a fit of violent anger, experienced dyspnœa and severe palpitation, with a pricking sensation about the heart. He died twelve years after the commencement of these symptoms, having previously suffered from anasarca, cold extremities, a great disposition to sleep, and his death having been preceded by profuse epistaxis. The right auricle was found enlarged to the size of the head of a newly born infant, and contained a pint and a half of semi-coagulated blood. The 
dilated auricle was lined with a scaly osseous substance like egg-shell, which kept it stretched. The pericardium was firmly adherent. Dionis attributes this immense dilatation to the distention and partial rupture of fibres; which occurred in consequence of the sudden ingress of blood into the auricle, during the violent fit of rage.

In the first class of cases of aneurism of the left auricle, or those in which an aneurismal dilatation existed in connexion with extensive narrowing of the mitral orifice, the attending symptoms would probably be chiefly dependent upon this circumstance, and the lesion would not be one of much practical importance; nor do I think that a diagnosis could be formed between it and simple dilatation of the auricle. Whether the diagnosis would be more certain in the remarkable cases which were consequent either apon external or internal injury, and in which the auricles attained such an immense size, $(1, * 1, * 2, * 3$, ) further experience, aided by auscultation, can alone enable us to decide.

\section{ANEURISM OF THE VALVES OF THE HEART.}

The valves of the heart themselves, as was previously observed, are sometimes the seat of dilatations, which may properly enough be styled aneurismal. Morand (C. $1^{*}$ ) and Laennec (2) have each published a case of this partial dilatation occurring in the mitral valve, in the form of a little pouch which projected into

- The references in this division of the paper, relating to aneurism of the valves, are to Appendix $\mathbf{C}$. 
the left auricle. In both these cases, the aortic valves were the seat of extensive ossification, so that great obstruction to the passage of the blood into the aorta must have existed. Indeed, I think it not improbable that this circumstance determined the dilatations, which possibly occurred in the valves rather than in any other part of the walls of the ventricle, in consequence of their being weaker than usual, either from congenital or acquired defect.

\section{CASE IX.}

Aneurismal dilatation of the right portion of the mitral valve, with perforations of the sac.

Mr. South has briefly alluded to another " case of this flask-like protrusion of the mitral valve into the left auricle, in which there are three small holes, and the preparation of which (No. 1444) is in the museum of St. Thomas's Hospital." (3.) This preparation I have examined carefully; the sac is seated in the large or right portion of the valve, and encroaches considerably upon the septum of the auricles, which is, as it were, pulled down, so as to form part of the sac; a circumstance which probably depended upon the tendinous ring, to which the margin of the mitral valve is attached, having likewise given way.

The sac would contain a large walnut; and in the substance of the interauricular septum directly above it there is a distinct ecchymosis. The only aortic valve which remains in the preparation appears perfectly healthy.-(See Plate IV.)

Sir Astley Cooper has alluded, in his published lectures, to a case of " aneurism in the left auricle;" and he has favoured me with an opportunity of having 
a copy taken of a drawing of the diseased parts, which is in his possession. I at once recognized the drawing as belonging to the case at St. Thomas's, alluded to by Mr. South, and the history of which is given in the following note which $I$ have received from Sir A. Cooper.

“ October 7th, 1837.

c MY DEAR SIR,

" Any draughtsman may take the drawing you wish, and you will of course give your own explanation of the preparation, which I have not sufficiently investigated to have made up my mind respecting.

“The heart was sent to me by Mr. Postlethwaite, and I added it with numerous others to the collection at St. Thomas's Hospital whilst I was delivering lectures at that institution.

"Yours truly,

“Astrey Cooper."

I have been kindly furnished by Mr. Postlethwaite, of Chichester, with a few additional particulars of the case, the history of which may now be stated as follows.-A soldier, aged about thirty, in the Sussex militia, to which regiment Mr. P. was surgeon, but whose previous history is unknown, suffered from symptoms of diseased heart, with ascites and œdema. In Mr. P.'s visits, he was frequently observed in a peculiar posture, clothed and out of bed, with his, bent knees resting on one side of the bed, his hands on the other side; a position which he thought favourable to the relief of his occasionally difficult respiration. The commanding officer was 
informed that his sudden death might be expected, for his pulse distinctly marked the irregular action of the heart. He died suddenly at Fort Pitt, Chatham, about the year 1812 .

The three preceding cases are the only ones on record, that I am acquainted with, in which an aneurismal dilatation of the valves of the heart had occurred. The two following cases will shew that this lesion is not confined to the mitral valve.

\section{CASE X.}

Cyanosis; congenital opening in the interventricular septum; four aneurismal dilatations (varices?) of the tricuspid valve.

In the museum of the Royal College of Surgeons, (No. 128 of the series of malformations,) is "an adult human heart, having an aperture of communication between the ventricles in the upper part of the septum," which is not further described in the catalogue, but which affords a very beautiful example of four aneurismal pouches in the tricuspid valve. The opening in the septum, which would admit of the introduction of the thumb, is directly below the origin of the aorta; its lower border being a smooth semilunar ridge. Upon passing a probe through this opening directly forwards into the right ventricle, it enters a membranous pouch, the size of a large nutmeg, the convexity of which is directed towards the centre of the ventricle. This pouch, which has a rather fibrous character, is formed either solely of that portion of the tricuspid valve which is connected with the septum, a supposition which is perhaps the more probable, or otherwise it is formed by 
the membranous portion of the interventricular septum, which has become distended into a pouch, and has gained an additional covering from adhesion to the portion of the valve alluded to. The lower portion of the pouch is perforated by two or three holes. If instead of passing the probe directly forward, it be directed downwards and somewhat to the left, it enters the cavity of the ventricle, through a narrow chink between the two portions of the valve. Opposite, and rather to the right of this chink, is another pouch of about the same size as the first, but of a more delicate structure, and evidently formed simply by the dilatation of the anterior portion of the valve. The convexity of this pouch is directed towards the parietes of the ventricle; so that during the systole of the heart, when the valve was acting, whilst the first pouch would project upwards into the auricle, this would depend into the ventricle. Behind this last described pouch, two small ones, the size of peas, and having the same direction, are concealed.

The mitral valve is slightly, and the tricuspid in a much greater degree, thickened at its free border. There is some opacity of the endocardium around the opening in the septum, which is more marked on the right than on the left side. The origins of the aorta and pulmonary artery are normal.-(See Plate V.)

Hitherto I have to regret that I have not been able to meet with any further history of this very curious pathological specimen, than that it was taken from a “blue boy," by Mr. Lawrence Healey, by whom it was deposited in the museum.

Upon further consideration I have discarded the 
idea which I at first entertained, that the opening in the septum of the ventricles, in this case, was not a congenital malformation, but that it was the result of a previous dilatation of that portion of the septum which is not furnished with muscular fibres, and which I have described in a previous part of this paper. (p. 222.) Whichever view, however, be adopted, the mechanism by which the dilatations of the tricuspid valve were produced is, I think, sufficiently obvious. During the ventricular systole, the blood was doubtless propelled by the left into the right ventricle, through the opening in the septum, and had impinged on both surfaces of the valve; and hence had resulted four dilatations; the first and largest of which was directed towards the centre of the ventricle, whilst the three smaller ones were directed towards its walls. The case, I think, satisfactorily establishes that when an abnormal communication between the right and left cavities of the heart exists, much admixture of the venous with the arterial blood does not necessarily ensue, but on the contrary, that the arterial blood is propelled into the right cavities of the heart, and is circulated with the black blood.

This condition, which is just the converse of that necessary for the production of cyanosis, has been too generally overlooked by authors in their speculations on malformations of the heart; but its possibility is distinctly adverted to by Corvisart, who even makes some observations upon the probable physiological effects of such an admixture*.

- Corvisart, Diseases of Heart. By Hebb. 1812. p. 256. 
In the case now described, however, both kinds of admixture had doubtless been present, possibly in consequence of some obstruction in the course of the pulmonary circulation.

For the particulars of the following interesting case $I$ am indebted to the kindness of Dr. Watson.

\section{CASE XI.}

Aneurismal dilatation of one of the two aortic valves, the third congenitally absent : cccentric hypertrophy of the left ventricle of the heart: mottled kidneys; subacute pericarditis, and fatal hydrothorax.

Thomas Glindon, aged 30, was admitted July the 14th, 1835, into the Middlesex Hospital, under the care of Dr. Watson. Anasarca of five weeks' standing in the legs, and of three weeks' in the hands and face; ascites; palpitation and breathlessness, especially on exertion ; requires a high pillow, posture in other respects indifferent; dreams a great deal. Pulse 100, with power, intermitting; bowels relaxed; urine scanty, very acid, albuminous.

He professes temperate habits. Six years ago he was confined to bed for six weeks with rheumatic fever, and had breathlessness then for the first time. He got perfectly well from this attack. He has heen subject to palpitation and dyspnœa for four or five years, and has had pain in the loins.

Auscultation.-July 17th. There is an unnatural sound with each action of the heart; with the systole, a rough harsh bellows sound, most audible near the middle of the sternum, and two inches and a half 
above the level of the nipple. Both these sounds are less distinctly heard over the apex of the heart.

On the 28th he was attacked suddenly with a great increase in the dyspnœea, drawing deep inspirations at long intervals; he was barely sensible, and talked rather incoherently; but these symptoms were quickly relieved by the application of cold washes to the head after the hair had been removed, and by a blister to the nape of the neck, with a few doses of tartar-emetic.

30th. The blowing sound attending the diastole of the heart is louder than before. He has some pain in the præcordial region, for which twelve leeches are to be applied.

During the months of August and September, he took digitalis and other diuretics and drastics, and at one time his mouth was brought freely under the influence of mercury, but without much advantage.

September 8th. The heart again examined; its sounds are tumbling, three in number, the systole being apparently composed of two, the second of which is faint, short and supplementary. The rhythm is anapæstic. The rush accompanying the diastole is no longer audible.

19th. During the night he had a very severe attack of dyspnoea (from the effusion of fluid into the left cavity of the chest). He lies on the left side, which is odematous. On the left side posteriorly no vesicular breathing is audible, but in this situation both the breathing and the voice are strongly bronchial ; (ægophony?). On the left side, in front, 
the respiration is inaudible. Heart's action rapid, obscurely marked, and heard all over the front of the chest.

25th. He died; the morbid sounds which were heard with each movement of the heart, soon after his admission, having been absent during the last month of his life.

Dissection.-The superficial veins, especially on the arms and shoulders, delineated by purple lines. Anasarca general ; much serum in the abdomen, and likewise in the right pleura, so as to float the lung high. There was still more serum in the left pleura, where at first the lung was not visible; it was small, flabby, slightly adherent at the summit, non-crepitant, and only a small part of its upper portion floated in water, the air being compressed entirely out of the remainder; it was not diseased in structure. The right lung was imperfectly crepitant.

The pericardium contained a large quantity of fluid, which was both turbid and reddish, and resembled thin pus stained with blood. I doubt whether it was actually purulent. There were no adhesions, but near the apex of the heart there was a rough spot, about half an inch square, consisting, apparently, of a deposit of lymph; and there was a corresponding spot on the opposite point of the free membrane.

The heart, large in itself and in all its cavities. The right ventricle as thick or thicker than natural. The left more thickened, but still more dilated than 
thickened. The valves natural or nearly so, except the aortic ; these were only two in number, and were thick and fleshy, and rough on their ventricular surfaces. The edge of the one was smooth, that of the other rugged; there was a deposit of ossific matter at their points of attachment. From the ventricular surface of the valve with the smooth border, there projected a little bag that would hold a swan-shot, and which opened by a little round mouth on the aortic surface of the valve. It had two little slits in its most depending portion, and was evidently formed by a dilatation of the valve itself. The two valves met tolerably close at their edges, so as not to allow of much regurgitation between them. The blood was fluid; the aorta small, its lining membrane and that of the heart stained of a deep red.

The kidneys were of a pale greenish colour externally, resembling verd-antique; a section having been made, the cortical part was found of a greenish white colour. Mr. Kiernan, who injected one of the kidneys, did not, by this means, detect any organic change. The mucous membrane of the small intestines was here and there red, with an arborescent injection of the vessels. The same membrane lining the cæcum appeared thickened.

I shall not do more here than observe upon the above case, which is replete with interest, that it would appear to have been one of those complicated ones in which the heart and kidneys are almost equally in fault ; although the disease of the heart, consecutive to a rheumatic endocarditis, was most probably 
the primary affection. The sudden effusions, however, which took place into the pleura, and probably also into the arachnoid, and the low unhealthy form of pericarditis which occurred in the later stages of the disorder, are points in the history of the case which associate the dropsy more with renal than with cardiac disease.

The formation of the aneurismal dilatation of the aortic valve must have been much facilitated by the congenital absence of one of their number; whence they must have been much less capable of adequately supporting and reacting against the column of blood in the aorta, during the diastole of the heart. This view is supported by a preparation in the museum of Guy's Hospital, (No. 1427 F,) shewing the same congenital absence of one of the valves of the aorta; in which one of them is the seat of a large perforation, having an irregular border studded with osseous excrescences, and which most probably was produced by a rupture. The double bellows sound which was most audible in the neighbourhood of these valves, I should suppose may be referred,- the first, or systolic, which was " rough and harsh," to the obstruction which was produced by the pouch itself, and likewise by the osseous patches in one of the interspaces of the two valves; the second, or diastolic, which is spoken of as "a rush," to the regurgitation which must have occurred through the perforations in the aneurismal sac.

I shall only add to this paper, a very few observations on the history of aneurism of the valves of the heart, in addition to those which are appended to the 
particular cases. I should be inclined to believe that, generally speaking, aneurisms of the valves of the heart originate in a progressively advancing dilatation, unpreceded by rupture or ulceration; and that in fact they are true aneurisms.

It is, however, possible that the aneurismal dilatation may have been preceded in some cases by the destruction of one of the laminæ of the endocardium forming the valve affected; and in such instances the lesion must of course be regarded as a false aneurism.

The constantly recurring movements to which these portions of the heart's structure are subject, are obviously unfavourable to the formation of coagula in aneurismal pouches in these situations; and indeed it does not appear that such coagula had formed in any of the cases.

It is perhaps scarcely necessary to point out that a lesion of this description must necessarily act, in a more or less decided manner, as an obstruction to the flow of the blood out of the cavity immediately behind the valve which is the seat of such lesion; and that if the aneurismal sac be perforated, either as the result of ulceration or rupture, a regurgitation of blood will be permitted from the cavity in front of the diseased valve. It will hence follow that the diagnosis of aneurism of the valves will, for practical purposes, resolve itself into that of obstructive and regurgitant valvular disease; upon which any observations of mine would be superfluous after the information we have respecting it, in the different 


\title{
standard works upon diseases of the heart in general, and especially in those of Drs. Hope and Williams.
}

\author{
Westminster Hospital, \\ November, 1837.
}

\begin{abstract}
A P P E N D I X;
Shewing the authorities for Seventy-four Cases of Aneurism of the Heart, with additional information respecting preparations examined by the author.
\end{abstract}

\section{A.-FIFTY-EIGHT CASES OF ANEURISM OF THE LEFT VENTRICLE.}

1. Galeati. Comment. Bonon. 1757, Tom. IV. p. 26. (Aneurism ruptured ; good history.) -2. Walter. Nouv. Mém. du Berlin, 1785. (Figure.) also Boas. Cordis Rariss. Aneurism. 1826, with good plate and description. (A. at apex. Prep. at Berlin.)-3. Baillie. Morb. Anat. 1793, and Engr. 1799. (A. at apex. Prep. at Glasgow.)-4. Beauchamp. Rec. Per. de la Soc. de Méd. Tom. V. 1799, said by Dezeimeris, (Arch. Gén. de Méd. Tom. XXI. p. 336,) to be the same case with that of Corvisart, Mal. du Cour, 1806. Hebb's Transl. p. 241. (The cases agree in many points, but by the one author the aneurism is compared in size to the heart itself, by the other it is stated to be one-third larger than the head of the femur.) -5. Corvisart. Op. Cit. p. 398, Case 56. (A. true ; in centre of interventricular septum. Not published as aneurism by Corvisart. No history.) -6. Hodgson. Dis. of Art. and Veins, p. 84, Case 13. (A. probably true; at apex. Not described as aneurism by the author. History.)-7. Zannini. Anat. Patol. di Baillie, Tom. I. p. 27, 1819. (A. size of fist near apex. A good history.)-8. Rostan. Sur les Ruptures du Cour. Obs. V. 1820. (Not published as aneurism; fatal rupture near the sac. History.) -9. Shaw. Manual of Anat. Vol. I. p. 119, 1822. (A. without tumour; ruptured.)-10. Cooper. Lect. on Surg. by Tyrrell, Vol. II. p. 27, 1824. (A. size of fist at middle of ventricle; pericardium adherent over sac, ruptured into left pleura. Sir A. C. to Author. History.)-11. Cooper. Loc. Cit. and Elliotson, Dis. of Heart, 1830. p. 28. (No history. Prep. at St. Thomas's Mus. 1445. A. about as large as heart, placed laterally to it, opening near apex, by mouth with thick lips; half filled with coagula, and pericard. adhering to tumour. Prep. examined by author.)-12. Laentnec. De l'Auscult., \&c. 1826. Forbes's 4th Edit. p. 513. (A small A. in an ulcerated passage in the interventricular septum. Varicose aneurism of the heart? Perhaps doubtful.)-13. Berard. Thesis 
(Paris.) sur l'Anat. Path. 1826. (A. size of apple at apex. No history.)14. Berard. Loc. Cit. (A. like the last. Some history.)-15. Cruveilhier. Nouv. Biblioth. Méd. Tom. II. p. 72, 1827, et Anat. Path. Liv. XXII. 1835. (A. size of walnut, side of $\mathrm{V}$. Good history.)-16. Johnson. Med.Chir. Review, April, 1827. (A. small, near aorta, and ruptured. History ; General Kyd.)-17. Biett. Rep. Gén. d'Anat. Tom. III. p. 99, 1827, et Breschet, Loc. Cit. p. 198. (A plate and history. A. size of orange. The celebrated Talma.)-18. Dance, by Breschet. Loc. Cit. p. 194. (A. size of walnut at apex. Good history.)-19. Breschet. Loc. Cit. p. 199. (A plate; no history. A. size of orange at base. Prep. in Mus. of Faculty of Med. Paris.)-20. Harrison, by Adams. Dublin Hosp. Rep. Vol. IV. p. 353, 1827. (A. nearly size of heart, at apex; almost presenting externally. A good history.)-21. Adams. Loc. Cit. (Prep. in Mus. Park Street, Dublin. A. size of walnut. Sudden death. No further history.)-22. Bignardi. Ann. Univ. di Med. 1829; and Bouillaud, Mal. du Cœur, Tom. II. p. 507. (A. size of bean ; true ; ruptured. Short history.) -23. Reynaud. Journ. Hebd. No. 22, 1829. A figure; also one by Carswell. Hypertrophy, plate 2, figure 1. (Two true A. in side of ventricle. No heart symptoms. Herniary aneurism of the heart.)-24. Reynaud. Loc. Cit. and Cat. Mus. Fort Pitt, Chatham, 1833. Prep. No. 38. (A. size of fist nearly, at centre of $V$. ; apparently true A. at first ; lining membrane, evidently being prolonged into it for some distance. Pericard. adherent over sac. Fibro-cellular degeneration of muscular fibres around; history. Examined by author.)-25. Anomymous. Med.-Chir. Review, Vol. XV. p. 252, 1829. (A. size of walnut, at base ; true. Slight history.) -26. Hodgkin. Cat. Mus. Guy's Hosp. No. 1396, A. 1829. (A. size of apple at apex; probably false; containing a non-laminated coagulum; pericard. had adhered. A short history. Prep. examined by author.)27. Elliotsm. Dis. of Heart, p. 28, 1830, and Med.-Chir. Review, Vol. XII. p. 174. Hist. and engr. Prep. in Mus. St. Thomas's Hosp. No. 1445, B. and C. (Two A. one size of apple, the other smaller, at side of V. near the base. Probably true; lining membrane traceable into larger sac, and evidently lining smaller one; which has two or three openings between the fleshy meshes. Pericard. adhered over tumour formed by larger sac. Examined by author.)-28. Brookes. (Josh.) Cat. Mus. p. 45. 1830. No. hist. Prep. now in Mus. Guy's Hosp. No. 1396, B. (A. size of heart at apex ; apparently formed by the uniform dilatation of the lower half of V.; diffused true aneurism. No lips to sac, but lining membrane and atrophied fleshy columns traceable over nearly the whole of its interior. Examined by author.)-29. Hunter (J.) Cat. Mus. R. Col. Surg. Lond. 1830. Path. Prep. in Sp. No. 363. (Two A. at base of V. see preceding paper. No history. Examined by author.)-30. Stanley. Cat. Mus. St. Barth. Hosp. 1831. Prep. No. 30. No hist. (A. size of pigeon's egg, about centre of $\mathrm{V}$. evidently true. Lining membrane opaque, and fibro-cellular change of the muscular fibres around the sac; over centre of which pericard. adhered. Herniary aneurism of the heart. Examined by author.)-31. Hope. Dis. of Heart, p. 592, 1832. (A. size of nut, directly under an aortic valve, and opening both into ventricle and aorta. Dissecting aneurism of the heart. History.)-32. Hope. Loc. Cit. p. 
286. (A. with same relations as last. Dissecting aneurism. Short history.) 33. Hope. Loc. Cit. p. 250 and 551, Case 10. (A. small, true, at apex; great general dilatation. History. Not published as aneurism by Dr. Hope.)-34. Petigny. Journ. Hebd. Tom. XIII. 1833. (A. about the size of heart; at apex. Good history.)-35. Cat. Mus. Fort Pitt, Chatham, No. 37, 1833. (A. size of large walnut ; at apex; probably false ; muscular substance ending abruptly around sac. Pericard. not adherent, but covered with false membranes over lower half of ventricle. Very little history. Examined by author.)-36. Hope. Morb. Anat. p. 85, 1834, Fig. 67. (A. size of egg; similar to Nos. 31 and 32 in its relations. Dissecting aneurism. Short history.)-37. Hope. Loc. Cit. (A. size of walnut. Dissecting aneurism. Short history.)-38. Choisy. Thesis (Paris.) No. 137, 1834. (A. size of egg; at base. Short history.)-39. Cruveilhier. Anat. Path. Liv. XXI. 1835. 3 Figures. (A. very extensive. Diffused true A. of heart? History.)-40. Cruveilhier. Op. Cit. Liv. XXII. Engr. (A. at apex. No history.)-41. Cruveilhier. Op. Cit. Liv. XXII. (A. small; at base. No history.)-42. Cruveilhier. Op. Cit. Liv. XXII. No history. (A. true ; lower half of interventricular septum.)-43. Sims. Med.-Chir. Trans. Vol. XIX. p. 401, 1835. (A. true; at base. History as to cerebral disease.)-44. Davies. Dis. of Lungs and Heart, p. 402, 1835, and author; Case 3. Prep. in possession of Mr. Langstaff. (A. true; at base. Herniary aneurism of the heart. Examined by author. History.)-45. Carswell. Illustr. Fasc. 9. Hypertrophy ; plate 3, fig. 2. Prep. in possession of Dr. C. (A. four in number; base and apex; true. Examined by author. No history.) -46. Carswell. Loc. Cit. plate 3, fig. 3. (Diffused true aneurism. No history.)-Author. The following eleven cases, now first published. 47 to 52. See preceding paper, Nos. 1, 2, 4, 5, 6, and 7.-53. Prep. No. 597, IX. M. A. University Coll., London. (A. size of large orange at base of V. No history.)-54. Prep. No. 14, Mus. St. Barth. Hosp. (Diffused true $A$. of lower half of $V$. Not described as aneurism in catalogue. No history.)-55. Prep. No. 18, Mus. St. Bart. Hosp. (Two aneurisms, one, incipient at base; one, size of large walnut at apex, ruptured. Not described as aneurism in catalogue. No history.) -56. Prep. No. 42. Mus. St. Bart. Hosp. (A. size of nut, directly under and between the right and left aortic valves, the right coronary artery passing over the sac. Extensive ossification of all the aortic valves; from a female, aged 18. No further history.)-57. Prep. No. 654 ", Mus. Guy's Hosp. (A. at apex, size of a walnut, ruptured. Vide Eliz. Beachman's case, 12th green inspectionbook.)-The following case added whilst this poper was going through the press : 58. Lobstein. Anat. Path. 1833, Tom. II. p. 501. (No history.)

- B.- ELEVEN CASES OF ANEURISM OF THE LEFT AURICLE.

1. Dionis. L'Anat. de l'Homme, p. 713, 1716. (Very extensive; after external injury.) -2. Abernethy. Med.-Chir. Trans. Vol. I. p. 32, 1809. (Contr. mitral orif.)-3. Burns. Dis. of Heart, p. 35, 1809. (Contr. mitral orif.)-4. Burns. Op. Cit. p. 168. (Contr. mitral orif.)-5. Hodgson. Dis. of Arteries and Veins, p. 83, 1815. (Appendix of auricle ; Contr. mitral orif. ) 6. Elliotson. Dis. of Heart, p. 29, 1830. Two engr. 
Prep. in Mus. St. Thomas's Hosp. No. 1445, A. (Sinus of auricle ; contr. mitral orif.)-7. Stanley. Cat. Mus. St. Bart. Hosp. No. 19, p. 56, 1831. (Sinus of auricle; contr. mitral orif.)-8. Stanley. Op. Cit. No. 33, p. 57. (Sinus of auricle; contr. mitral orif.)-9. Hope. Dis. of Heart. Case 25, p. 599, 1832. (Contr. mitral orif.)-10. Cruveilhier. Anat. Path. Liv. XXII. 1835. (M. Chassaignac's case. Sacculated aneurism, size of a nut.)-11. Davies. Dis. of Lungs and Heart, p. 402, 1835; and author, Case 8. Prep. Mus. Coll. Surg. (Langstaff. No. 1449.) (Appendix of auricle ; contr. mitral orif.)

Three cases of extensive dilatation (Varix?) of the right auricle: *1. Borrichius. Act. Hafniens. Barthol. Obs. 48, p. 150, 1676. (After external violence.)-"2. Dionis. L'Anat. de l'Homme, p. 713, 1716. An engr. (After violent anger.)-3. Bernhardi. Obs. Ingent. Cordis Tumor. Regiom. 1826. An engr. - (None of the above Cases, excepting Nos. 6, 10, and 11, appear to have been described, by their respective authors, as instances of aneurism, in the proper acceptation of the term.)

\section{C. - Five cases of anEURISMat Dilatation of the valves of THE HEART.}

1. Morand. Hist. de l'Acad. Roy. des. Sc. pour 1729; 1731. (Mitral valve.)-2. Laernec and Fizeau. Bul. de la Fac. de Méd. Tom. I. p. 207, et Bouillaud. Traité Clin. des Mal. du Cœur. Tom. IJ. p. 510. (Mitral valve.)-3. Sir A. Cooper. Lect. by Tyrrell, Vol. II. p. 27. South in Otto's Path. Anat. 1831, p. 281 ; and author, Case No. 9. (Mitral valve. Prep. in Mus. St. Thos. Hosp. 1444.)-4. Author. Case 10. Prep. in Mus. Coll. Surg. No. 128. (Tricuspid valve; four sacs.)-5. Author. Case 11. Dr. Watson's case. Prep. in possession of Mr. A. Shaw. (Aortic valve.)

\section{D. - SEVEN CASES FROM THE OLDER AUTHORS, DESCRIBED CHIEFLY}

AS CONNECTED WITH THE AURICLES OF THE HEART, SOME OF WHICH WERE PROBABLY ANEURISMS.

1. Trafellmannus; quoted by Schenck. Obs. Med. Rar. 1644. Obs. 8, p. 257.-2. Puerarius. Obs. Select. add. Thesaur. Med. Lib. III. p. 345. -3. Act. Nat. Cur. Cent. 8; p. 78.--4. Op. Cit. Dec. 2. Ann. 6; p. 415. 5. Op. Cit. Dec. 3. Ann. 5 and 6. Obs. 134-6. Bonetus. Sepulchretum, 1700. Lib. II. Sect. 8. Obs. 30; and Sect. 11. Obs. 1. (This is most probably the case, quoted erroneously (?) by Lieutaud and Corvisart, from the Act. Nat. Cur._Compare with Bonetus, Lieutaud. Hist. Anat. Med. Cardis Tumores. Obs. 554 ; and Corvisart, Diseases of Heart, by Hebb. p. 242. The case was evidently one of aneurism of some kind; possibly, however, of the very commencement of the aorta.-7. Douglass. Phil. Trans. 1714-16 ; Vol. XXIX. p. 326. Quoted erroneously by Good, (Study of Medicine, 1825, Vol. III. p. 475,) as a case of aneurism of the left ventricle. An aneurismal dilatation of the left auricle, however, possibly existed. 


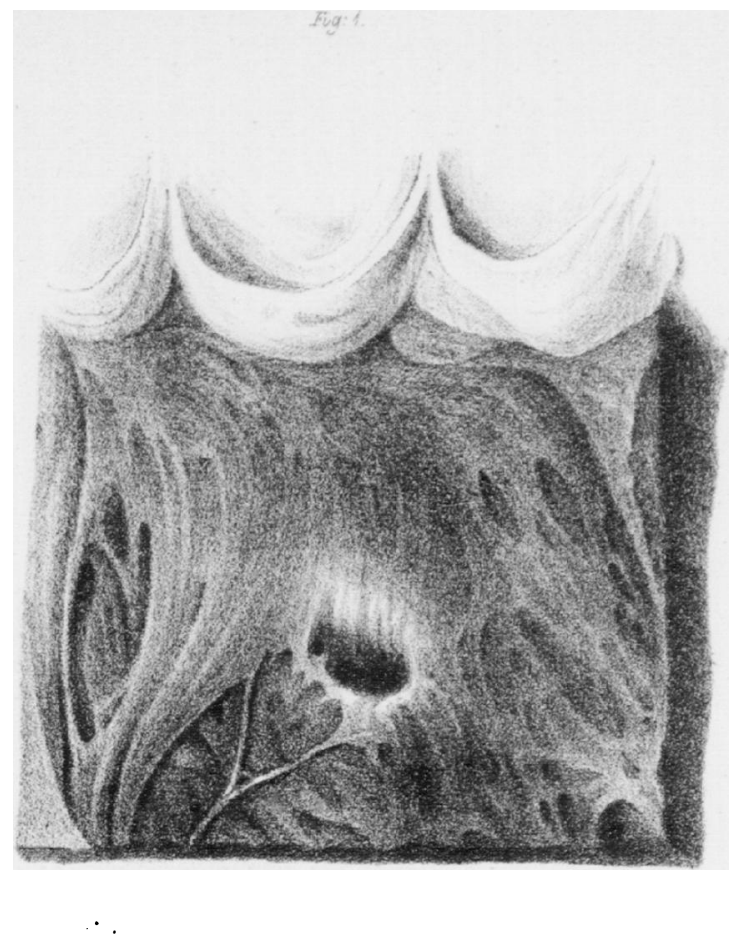

Plare 3 roing

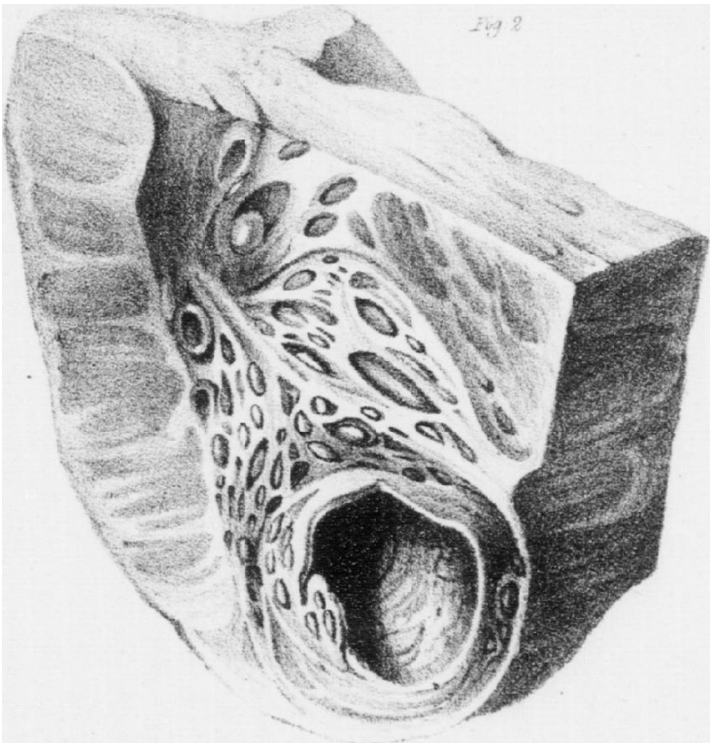


$\mathrm{Pl} 4 \mathrm{Vol} \mathrm{XXI}$

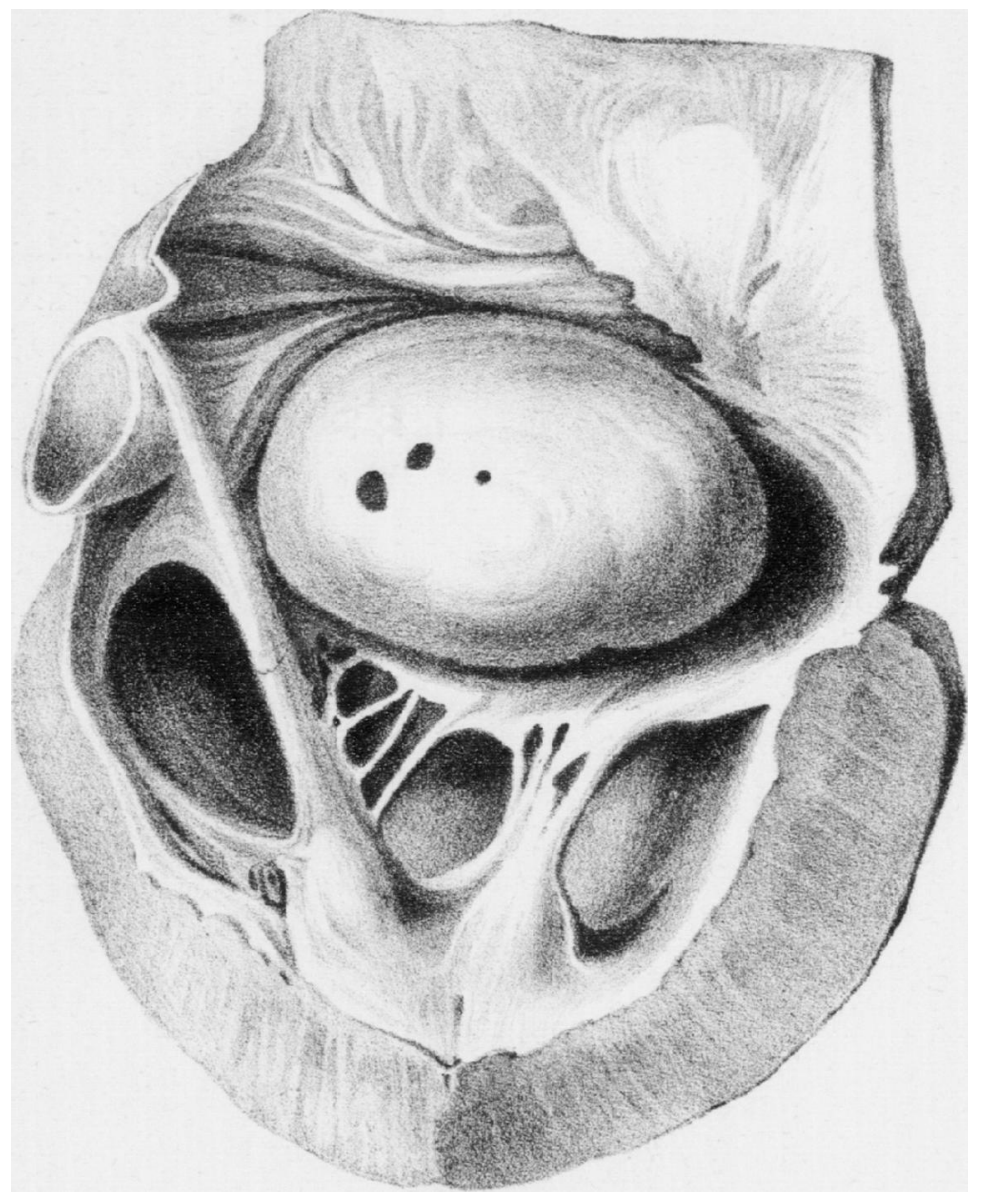




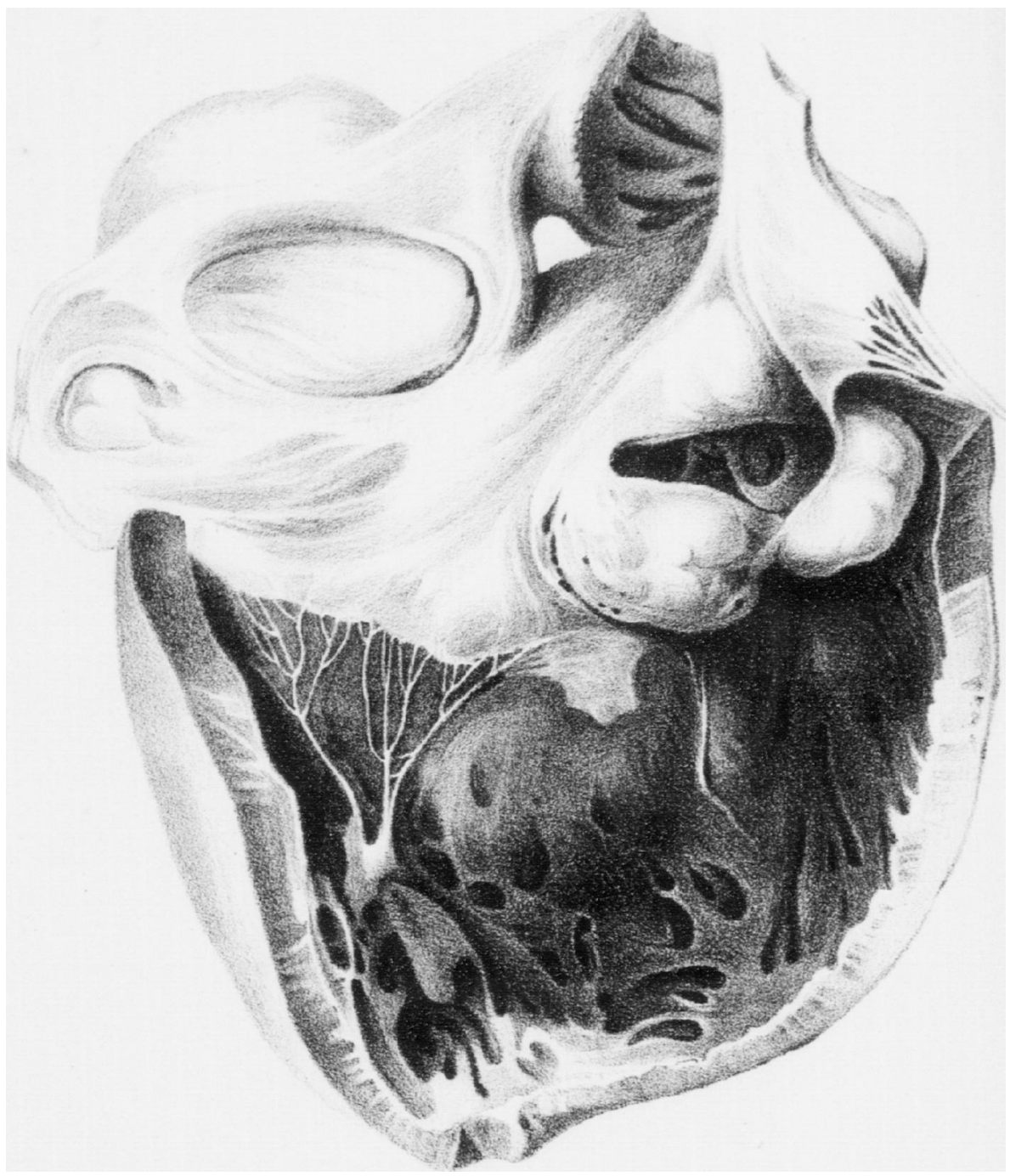

